\title{
WestVirginiaUniversity
}

THE RESEARCH REPOSITORY @ WVU

Graduate Theses, Dissertations, and Problem Reports

2018

\section{Evaluation of WVUteach: Enrollment, Retention, and Students' Intentions}

\author{
Catherine Garner
}

Follow this and additional works at: https://researchrepository.wvu.edu/etd

\section{Recommended Citation}

Garner, Catherine, "Evaluation of WVUteach: Enrollment, Retention, and Students' Intentions" (2018). Graduate Theses, Dissertations, and Problem Reports. 5650.

https://researchrepository.wvu.edu/etd/5650

This Thesis is protected by copyright and/or related rights. It has been brought to you by the The Research Repository @ WVU with permission from the rights-holder(s). You are free to use this Thesis in any way that is permitted by the copyright and related rights legislation that applies to your use. For other uses you must obtain permission from the rights-holder(s) directly, unless additional rights are indicated by a Creative Commons license in the record and/ or on the work itself. This Thesis has been accepted for inclusion in WVU Graduate Theses, Dissertations, and Problem Reports collection by an authorized administrator of The Research Repository @ WVU. For more information, please contact researchrepository@mail.wvu.edu. 


\title{
Evaluation of WVUteach: \\ Enrollment, Retention, and Students' Intentions
}

\section{Catherine Garner}

\begin{abstract}
A thesis submitted to the College of Education and Human Services at West Virginia University

in partial fulfillment of the requirements for the degree of

Master of Arts in

Educational Psychology: Program Evaluation and Research
\end{abstract}

Karen Rambo-Hernandez, Ph.D., Chair

Reagan Curtis, Ph.D.

Abhik Roy, Ph.D.

Department of Learning Sciences and Human Development

Morgantown, West Virginia

2018

Keywords: WVUteach, program evaluation, teacher certification

Copyright 2018 Catherine Garner 


\section{ABSTRACT \\ Evaluation for WVUteach: Enrollment, Retention, and Students' Intentions}

Catherine Garner

Background/Purpose: Mathematics and science achievement of K-12 students in the United States is lagging the achievement of students in other developed countries. A shortage of highly qualified teachers in the areas of science, technology, mathematics, and engineering (STEM) is a contributing factor to lower achievement. One solution is to provide an efficient means for STEM students to earn a teaching certification without adding time to their current four-year degree programs. In 2015, West Virginia University introduced WVUteach, a program designed to encourage students in STEM majors to earn their teaching certifications while they are earning their degrees in their major fields of study. This study evaluated West Virginia University's WVUteach program in the areas of the enrollment of STEM students, the retention of students in the program, and the intention of students to pursue a career in teaching.

Methods/Analysis: WVUteach provided enrollment data for an analysis of trends, and current WVUteach students and Master Teachers participated in a focus group and interviews. The focus group and interviews were analyzed for common themes and insights into research questions about the reasons students give for enrolling in introductory courses and for continuing in or discontinuing WVUteach. Insights into the factors that influence students' decisions to obtain a teaching degree and go on to teaching careers including self-efficacy in STEM teaching were also examined.

Results: The results of a focus group with current WVUteach students and WVUteach Master Teachers provided insight into the recruitment and enrollment trends, student retention, and future intentions of students upon completion of WVUteach.

Discussion: The discovery phase of the program evaluation for WVUteach included insights obtained through a focus group and interviews with key stakeholders. Recommendations for WVUteach included an examination of recruiting processes, an increase in visibility of WVUteach, an examination of trends in enrollment and retention, and an exploration of job placement assistance for students considering teaching careers in West Virginia schools. Conclusion: This evaluation provided a starting point for a full program evaluation of WVUteach. The data collected from current WVUteach students and WVUteach Master Teachers indicated areas that warranted further investigation. The results of a full program evaluation of WVUteach could be used to help new UTeach programs and programs seeking to provide alternative paths to teacher certification with a model of practices that were effective in the initial years of implementation of the WVUteach program. 


\section{Acknowledgments}

My deepest appreciation goes to my mentor, advisor, and committee chair, Dr. Karen Rambo-Hernandez. She inspired me and supported me through the completion of my coursework and my thesis. Dr. Rambo-Hernandez is truly a teacher at heart and a skilled researcher. I acknowledge the additional members of my committee, Dr. Reagan Curtis and Dr. Abhik Roy, who pushed me out of my comfort zone to find skills I did not know I had. The insight and guidance they provided improved my approach to my thesis.

A special acknowledgement goes to WVUteach faculty and staff. Thanks to Dr. Gay Stewart, WVUteach Director, for supporting my data collection. Thanks to Amanda Jelsema, WVUteach Coordinator, for connecting me with students and teachers, for providing me with data, and for her advice and guidance. I would also like to thank the WVUteach Master Teachers for their support in the recruitment of students and for sharing their own experiences with WVUteach.

I would also like to thank my family and friends for their support. Thanks to my adult children for their encouragement as I pursued my graduate education. Thanks to my dad for providing me with a quiet place to work and access to resources that I needed to work more efficiently. Thanks to my mom for the late-night conversations that kept me going. I also wish to thank my peers, Heather Henderson, Lydia Olson, and Megan Mikesell. They shared their experiences, statistics support, and encouragement throughout my thesis process. I am fortunate to have a wonderful support system in my friends and family. 


\section{Table of Contents}

Acknowledgments ...............................................................................................................................ii

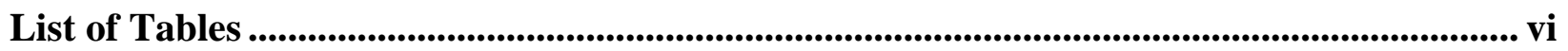

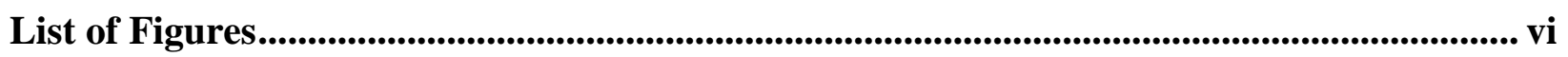

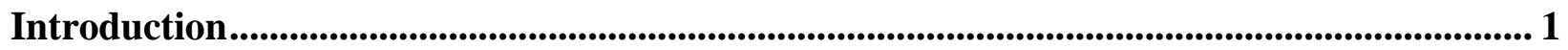

Purpose and Significance of this Study ............................................................................... 1

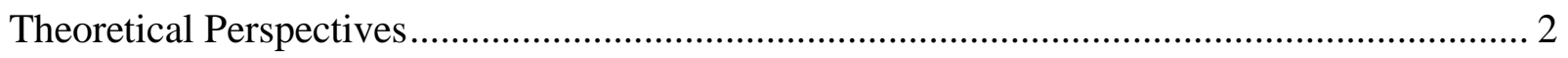

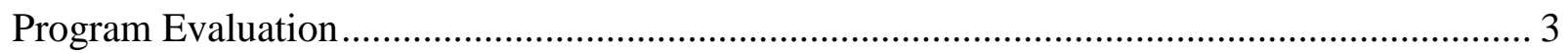

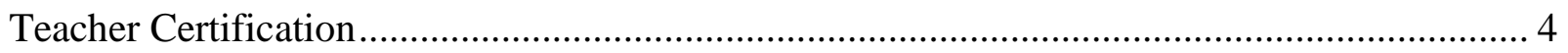

WVUteach........................................................................................................................................... 6

Methodology ........................................................................................................................................... 7

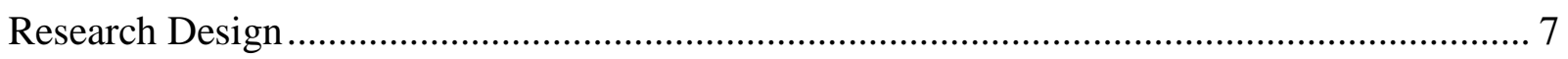

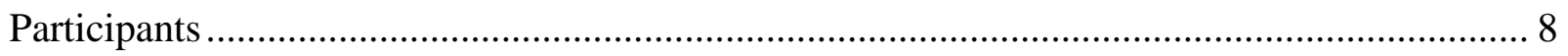

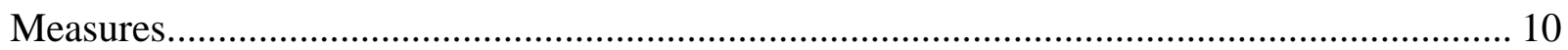

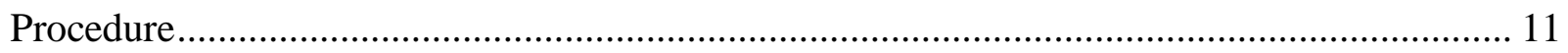

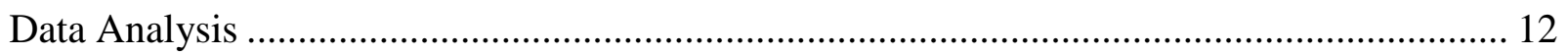

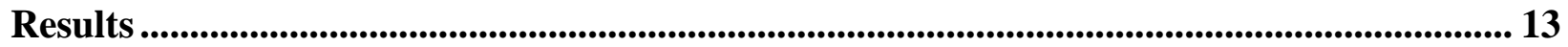

Evaluation Question 1: Looking at historical data, what trends have occurred in enrollment and retention in Inquiry Approach to Teaching, Inquiry-Based Lesson Design, and further

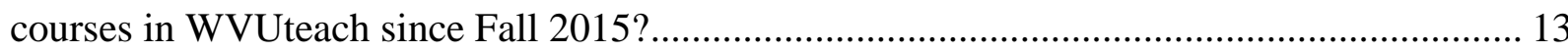

Evaluation Question 2: According to WVUteach students and Master Teachers, what reasons did students state for their decisions to enroll in WVUteach? ................................................ 14

Evaluation Question 3: According to WVUteach students and Master Teachers, what interests and prior experiences contributed to students' decisions to pursue teaching certification

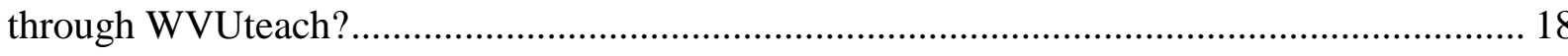

Evaluation Question 4: According to WVUteach students and Master Teachers, what reasons did students state for their decisions to either continue or discontinue their participation in WVUteach?

Evaluation Question 5: According to WVUteach students, what was their self-efficacy in STEM teaching?

Evaluation Question 6: According to WVUteach students and Master Teachers, what were students' career intentions upon completion of the WVUteach program? 


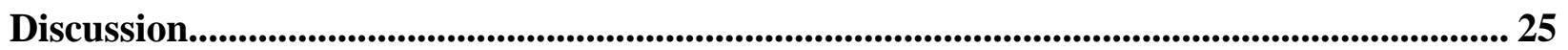

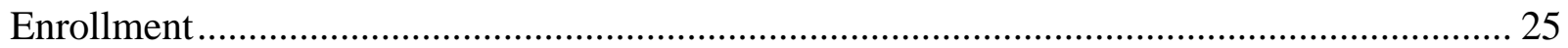

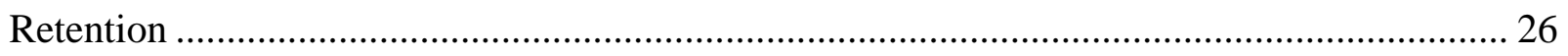

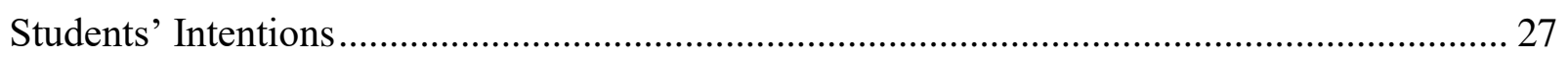

Recommendations and Other Potential Considerations for WVUteach ................................ 28

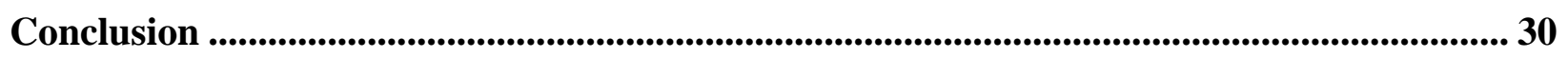

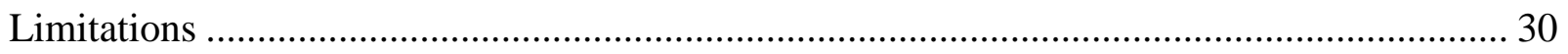

Recommendations for Future Research ........................................................................... 31

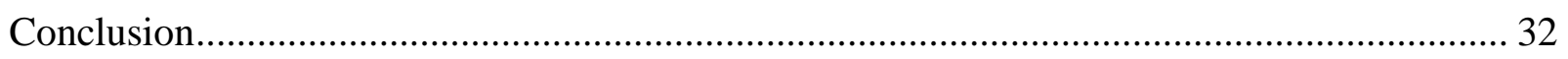

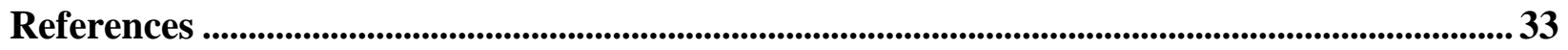

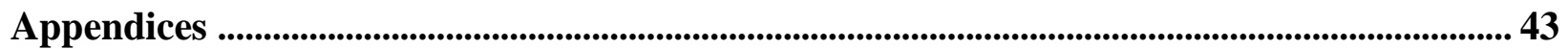

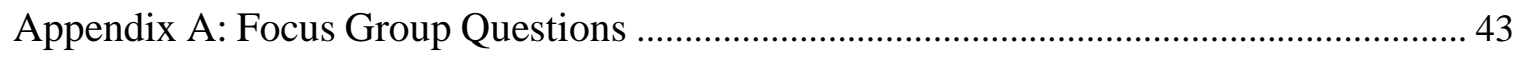

Appendix B: Master Teacher Interview Questions .......................................................... 45 


\section{List of Tables}

Table 1: Identified Topics Provided from the Research ......................................................... 35

Table 2: WVUteach Course Enrollment and Completion by Term ............................................ 36

\section{List of Figures}

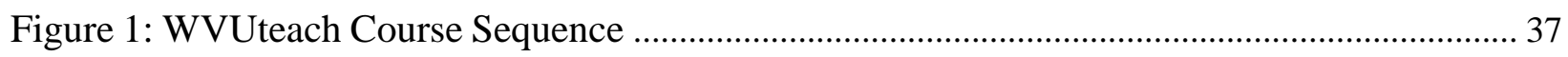

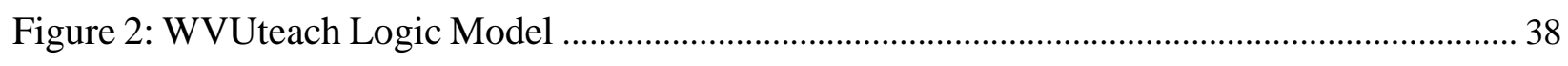

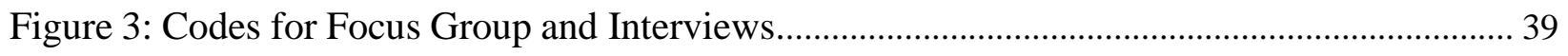

Figure 4: Number of Students Enrolled in WVUteach Introductory Courses ............................... 40

Figure 5: Percentage of Students Retained from Step 1 to Step 2 ............................................... 41

Figure 6: Persistence in WVUteach through the First Two Years ................................................. 42 


\section{Introduction}

The United States continues to lag behind other developed countries in mathematics and science achievement. Recruiting and retaining highly qualified teachers in the areas of science, technology, mathematics, and engineering (STEM) is an ongoing problem (Ingersoll \& Perda, 2010; U.S. Department of Education, 2013; Westerlund, Radcliffe, Smith, Lemke, \& West, 2011). According to the National Center for Education Statistics (NCES) 2011-2012 study of grade 9-12 public school classes, only 60 percent of mathematics courses and 34 percent of physical science classes were taught by a teacher with a major and certification in the subject area (Hill \& Owens, 2015). The teaching profession is not attracting the higher achieving graduates in STEM (Guarino, Santibanez, \& Daley, 2006; Eick, 2002; Westerlund et al., 2011). Of those who do choose to pursue teaching careers, the higher achieving graduates are more likely to leave the teaching profession within the first few years of teaching (Ingersoll \& Perda, 2010).

In response to this need for highly qualified STEM teachers, West Virginia University implemented WVUteach, a program based on the UTeach program developed by The University of Texas at Austin and implemented nationally. The program was designed to attract STEM students to the teaching profession. The UTeach model allows students majoring in STEM fields to develop the skills and knowledge necessary to become K-12 educators without detracting from their current studies in their major fields. West Virginia University adopted the UTeach model in 2015, recruiting the first class of students for the fall semester of 2015.

\section{Purpose and Significance of this Study}

The purpose of this evaluation was to examine West Virginia University's WVUteach program in the areas of the enrollment of STEM students, the retention of students in the program, and the intention of students to pursue a career in teaching. Enrollment was defined as the number of students registered for a course at the beginning of the semester regardless of whether or not the students completed the course. Retention, for the purposes of this evaluation, included the number of students who completed one course and subsequently enrolled in the next course. Students' intention to pursue a career in teaching was based on verbal reports from current WVUteach students and Master Teachers regarding students' stated career plans. 
Data on enrollment in WVUteach courses was examined for trends in enrollment in the program's introductory and core WVUteach courses. Data was also obtained from students and teachers to explore the reasons students gave for enrolling in introductory courses and for continuing in or discontinuing the program. Students and teachers also shared insights on the factors that influenced students' decisions to obtain a teaching degree and pursue a teaching career including self-efficacy in STEM teaching.

This evaluation highlighted the strengths of the WVUteach program in enrollment, retention, and students' intentions to pursue teaching careers and provided recommendations on changes that could be made to further strengthen the program. The results of this study could also benefit new teacher certification programs through an understanding of the successes and areas of need experienced by WVUteach in its early years.

This program evaluation proceeds as follows. The first section outlines the program evaluation and the background of teacher certification programs. The next section includes a description of WVUteach and its application of the UTeach model for STEM teacher certification. The methodology, results, and discussion of the process and findings of this program evaluation follow. The evaluation concludes with recommendations for WVUteach and suggestions for future research.

\section{Theoretical Perspectives}

Learning about the WVUteach program in its early years involved gathering information from students and teachers about what they knew about the program. Understanding how these individuals came to know the things that they knew was rooted in the evaluators's epistemology. The students and teachers knew what they knew through their experiences and how that knowledge was constructed. Crotty (1998) explained constructionism as the result of human beings constructing meaning through their interactions with the world. He went on to further explain constructivism as a focus on the meaning that an individual constructed from activities. This understanding of the constructions of the individual within a social context provided a framework for this study.

Social interaction is a principle of social constructivism. In their book "The Social Construction of Reality: A Treatise in the Sociology of Knowledge", Berger and Luckmann (1966) described "human reality as socially constructed reality" (p. 210-211). Lev Vygotsky 
(1978) stressed the importance of social interactions and the support of others in learning. Stajkovic and Luthans (1998) explained Bandura's social cognitive theory of learning. They explained that the "social" in social cognitive theory referred to the role of environment on a person's thoughts and behaviors. They explained the "cognitive" as the role of a person's thoughts on their motivation and behaviors. Of particular interest in this evaluation was the role of self-efficacy, a person's belief in his ability to complete a task, which directly relates to social cognitive theory. Bandura (1993) explained that a person's efficacy beliefs influence their cognitive, motivational, affective, and selection process. Bandura described a study conducted by Collins in 1982 were Collins found that people who did not perform well may have either lacked skills or lacked the belief that they could utilize the skills they did have. Collins' study supported Bandura's assertion that people with stronger perceived self-efficacy would have a greater commitment to completing challenging tasks. A person's willingness to engage in cognitive skills, motivation to complete challenging tasks, emotional responses to difficult tasks, and decision to engage in or avoid particular activities were all tied to their self-efficacy.

This evaluation of WVUteach utilized the experiences of students and teachers and the way they came to know what they knew about their role in the WVUteach program to better understand the impact of WVUteach in preparing STEM teachers. Social cognitive theory and this understanding of self-efficacy provided a framework for understanding the need for students to develop self-efficacy in STEM teaching before they would be ready to commit to a career in teaching.

\section{Program Evaluation}

This evaluation of the WVUteach program was framed in the context of social constructivism and social cognitive career theory. In line with the constructivist paradigm, a constructivist evaluation formed the basis for this evaluation. The goal of a constructivist evaluation is not to search for absolute truth or correct answers (Stufflebeam, 2001). Rather, the goal is to provide a formative evaluation that will "exam a program's development and assist in improving its structure and implementation" (p. 40). A constructivist evaluation consists of two phases: discovery and assimilation (Guba \& Lincoln, 2001). In the discovery stage of the constructivist evaluation, the evaluator sets out to describe the program and its processes in place at the time as interpreted by stakeholders. This stage tends to lead to more questions than 
answers. Typically, in a constructivist evaluation, those questions would be further explored in the second stage, assimilation, which would involve stakeholders working together to resolve the problems that arose in the discovery phase (Guba \& Lincoln, 2001). Only the discover stage was explored in this program evaluation.

The positionality of the evaluator was an important consideration in the gathering and interpretation of data. The evaluator in this program evaluation participated in a traditional teacher education program by earning an education degree without obtaining a STEM degree. The evaluator also participated in WVUteach as a co-instructor for the third course in the WVUteach course progression. These experiences provided opportunities to see the process of teacher certification from different perspectives. However, these experiences also influenced how the evaluator conducted and interpreted qualitative data from focus group and interviews. The evaluator's perspective was considered in the reporting of the results from the focus group and interviews.

A focus group with students who were currently in WVUteach courses, interviews with Master Teachers who worked closely with students when they took their introductory courses, and input from the WVUteach Program Coordinator supplied insight into the program and its participants. The way the evaluator described the WVUteach program and the people involved in the programs was influenced by the evaluator's interpretation of observed social interactions. This interpretivism perspective provided a framework in which the descriptions of the people and their experiences were influenced by the evaluator's interpretation of the social context of the program and its participants.

\section{Teacher Certification}

This program evaluation looked at the early years of WVUteach, a program providing an alternative path for students in STEM majors to earn teaching certification. An understanding of the pathways a student could take to obtain a secondary education teaching certification provided a context for the role of the certification option afforded by WVUteach. Options previously available to students included an undergraduate degree in secondary education with an emphasis in a particular area, an undergraduate degree in a focus area such as English or science followed by a graduate degree in secondary education, or alternative certification paths for target groups with such programs as Troops to Teachers. 
Under the first option, an undergraduate degree in secondary education, students majored in education and specialized in a specific content area. Students devoted considerable class time to learning about human development and teaching theories. The students were not required to obtain a major in the specific content area which reduced the number of credits they were required to complete in their content areas.

In the late 1980's, The Benedum Collaborative was formed to look at the disparity between research into how students learned and the connection to practice (Benedum Collaborative, 2016). The findings indicated that the coursework in the secondary education programs emphasized teaching pedagogy without the opportunity for practice. To graduate more highly qualified teachers, WVU implemented a five-year dual degree program in secondary education degree. Students simultaneously earned a Bachelor of Arts or Bachelor of Science degree in their content area and a Master of Arts in Education. The five-year degree in secondary education worked to integrate pedagogy and practice starting early in the program. Students applied for enrollment in the program after completing four semesters in their degree program. Students were then committed to six additional semesters of study. The five-year secondary education dual degree program stopped enrolling new students in Fall 2017.

Following the third option for teacher certification, which was still available to students at the time of this evaluation, students could earn a Bachelor of Art or Bachelor of Science degree in their content area then earn a Master of Arts degree in secondary education. Unlike some secondary education programs, WVU students were required to earn their undergraduate degree before earning their graduate degree in secondary education. Students in STEM majors completed their undergraduate degrees and either chose to enter the work force or chose to earn a master's degrees in a specific field of study.

None of the previously mentioned options available to students provided an opportunity for STEM majors to develop the skills necessary to become highly effective teachers while still pursuing the degrees they desired in their major field of study without adding time to their college experience. STEM students could benefit from a program that would allow students to participate in activities where they could develop the skills necessary to become highly effective teachers while completing their degrees in their major fields of study. Ultimately, the outcome of the program would be to increase the number of highly qualified STEM teachers in West Virginia by providing a new opportunity for students in STEM majors. 


\section{WVUteach}

One possible program that would provide a new opportunity for STEM majors was the Uteach program developed by The University of Texas at Austin. UTeach was developed to allow students in STEM fields to earn a teaching certification and a degree in their major field of study in the same amount of time that they would have traditionally earned their STEM degrees. UTeach was developed to attract these students and prepare them to become exceptional teachers in secondary science, computer science, and mathematics classrooms. UTeach Institute (2017) indicated that the program was effectively placing STEM teachers in classrooms with eighty-five percent of UTeach graduates still teaching in the schools after five years.

The UTeach model provided universities with training and ongoing support. The Uteach model included a variety of methods to recruit STEM students, intensive support to maximize the number of students earning their teacher certification, and support for graduates during their first two years in the teaching profession. West Virginia University adopted the UTeach model in 2015 to provide an option for students in STEM majors to earn a teaching certification while completing their current degree program. WVU students were enrolled in the first introductory course in the fall semester of 2015.

Recruitment of students into the WVUteach program was mainly focused on first and second year students because students needed at least 5 semesters left in their program to complete the courses. WVUteach sought to reach students through a variety of means. Students who declared a STEM major at the time of the New Student Orientation received an email with information about the opportunities that WVUteach provided. STEM introductory courses were then targeted, and a representative from WVUteach presented information to the students during a class session, when instructors agreed. Students who were interested in learning more about the program provided their contact information during the class presentations. Additional opportunities, such as tables set up at common evening exams were also used.

Throughout the school year, STEM students continued to be exposed to information about the opportunities afforded by WVUteach. WVUteach utilized social media, mainly Facebook and Twitter, to advertise Open Houses and attendance at WVU recruitment events such as Meet WVU, New Student Orientation, and Major Match. WVUteach representatives were available at the information fairs and orientation events for Eberly College, Davis College, College of Education and Human Services, and Statler College to provide information and 
answer questions about the program. The recruitment process was designed to ensure that STEM majors were aware of what WVUteach could offer them and to provide an opportunity for students to ask questions of WVUteach faculty and students.

During the recruitment process, students were invited to enroll in an introductory course taught by a Master Teacher. WVUteach advertised the first introductory course Inquiry Approach to Teaching, nicknamed Step 1, as a one-credit course in which students would explore inquiry-based teaching and implement what they had learned by planning and teaching lessons at a local elementary school. Providing opportunities for students to experience actual teaching and opportunities to reflect on that teaching has shown to aid student retention (Luft, Wong, \& Semken, 2011). Step 1 was an opportunity for students to experience teaching in a real classroom. According to information provided by WVUteach, about half of the students who enrolled in Step 1 did not continue on to a second one-credit course, Step 2, Inquiry-Based Lesson Design. If students decided teaching may be of interest to them, they enrolled in Step 2, where they taught in a local middle school. WVUteach staff noted that students typically decided by the end of Step 2 if they were interested in pursuing their teaching certification through WVUteach. The staff reported that once students enrolled in a course beyond Step 2, students were highly likely to complete the program. After Step 2, students continued on to take 15-18 additional credit hours and completed one semester of teaching practice, which counted for an additional 10 credit hours (Figure 1). Students continuing in the program took additional courses in educational psychology, instructional strategies, integration of mathematics and science content, and content specific methods. Most of the additional 15-18 credit hours counted as general electives providing students with the ability to earn both their teaching certification and their degree without extending their time in college. WVUteach curriculum provided a pathway for students in a variety of STEM majors to obtain teacher certification while completing their STEM degrees

\section{Methodology}

\section{Research Design}

The first step in designing this study was to develop a logic model for WVUteach outlining the resources and activities necessary to achieve the desired outcomes and ultimate impacts of WVUteach (Figure 2). One of the critical outcomes of the program was an increase 
in the number of STEM certified teachers in West Virginia. At the beginning of the 2016-2017 academic year, West Virginia schools reported 593 teaching vacancies. In his newspaper article, Dr. Michael Martirano, West Virginia school superintendent, addressed the specific shortage of mathematics instructors with 64 vacancies at the time of his report. He cited an aging teacher population combined with a lack of certified mathematics teachers coming out of the colleges as two of the factors that contributed to the mathematics teacher shortage (Gallahan, 2016). Other critical outcomes for WVUteach were an increase in the pool of certified teachers in areas of critical need and shortage and a decrease in the number of STEM teaching positions filled by individuals who were not considered highly qualified. This study was designed to evaluate West Virginia University's WVUteach program in the areas of enrollment of STEM students into the program, retention of students in the program, and the intention of students to pursue a career in teaching including students' self-efficacy in STEM teaching. The following evaluation questions addressed these areas:

(1) Looking at historical data, what trends have occurred in enrollment and retention in Inquiry Approach to Teaching, Inquiry-Based Lesson Design, and further courses in WVUteach since Fall 2015?

(2) According to WVUteach students and Master Teachers, what reasons did students state for their decisions to enroll in WVUteach?

(3) According to WVUteach students and Master Teachers, what interests and prior experiences contributed to students' decisions to pursue teaching certification through WVUteach?

(4) According to WVUteach students and Master Teachers, what reasons did students state for their decisions to either continue or discontinue their participation in WVUteach?

(5) According to WVUteach students, what was their self-efficacy in STEM teaching?

(6) According to WVUteach students and Master Teachers, what were students' career intentions upon completion of the WVUteach program?

\section{Participants}

Students enrolled in WVUteach courses during the Fall 2017 academic term were recruited to participate in three different focus groups: (1) students currently enrolled in WVUteach Step 1, (2) students currently enrolled in WVUteach Step 2, and (3) students 
currently enrolled in a WVUteach course beyond Step 2 with each focus group comprised of six to eight students. WVUteach provided a list of current students, and invitations for participation in focus groups were sent to the 42 Step 1 students, 14 Step 2 students, and 29 students reportedly enrolled in at least one course beyond Step 2 with approximately an equal number of male and female students invited. Students were offered lunch and entry into a drawing for one of three gift cards. All current students were invited to participate in the focus groups via individualized emails, and details of the nature of the study and the topic of the focus group discussions were provided at that time. Three students in courses beyond Step 2 accepted the invitation to participate in a focus group. No students in Step 1 or Step 2 responded to the request to participate in a focus group. Additional invitations were sent to the 56 Step 1 and Step 2 students inviting them to participate in an interview at a time of their choosing. Again, no students agreed to participate. Recruitment may have been more successful had the invitation been given more directly through visits to the classroom or other WVUteach activities.

A focus group was conducted with three students who had completed Step 1 and Step 2 and continued in the WVUteach program. All three students were currently enrolled in at least one course beyond Step 2. Two of the participants were non-traditional students who had taken a break from their education and returned to school. Two of the participants were pursuing a mathematics degree and one was pursuing a science degree. Two of the participants were female and one was male. To maintain the confidentiality of the participants, male pronouns are used to report information provided by all participants. All three students were nearing the completion of their STEM degrees and completion of their WVUteach coursework.

Additionally, WVUteach Master Teachers' who work closely with students in the Step 1 and Step 2 courses were invited to participate in interviews during the Spring 2018 academic term. All four of the Master Teachers were invited to participate in an interview, and all four agreed to meet. Three of the four Master Teachers taught Step 1 courses, and one Master Teacher taught Step 2. One of the four Master Teacher also taught the Apprentice Teaching course, which students took just before graduating from the program. Three of the teachers were female, and one teacher was male. Male pronouns were used throughout the reporting of the results of the interviews to maintain confidentiality. Because of their interactions with the students, the teachers provided insights that would address the evaluation questions. The information that the Master Teachers shared in the interviews provided the rich data needed to 
address the evaluation questions, and they provided additional information about the recruitment processes used to promote WVUteach enrollment.

\section{Measures}

Two methods of data collection were used to evaluate the WVUteach program. Descriptive data on the number of students enrolled and retained in the WVUteach Step 1, WVUteach Step 2 and WVUteach courses beyond Step 2 were collected from the WVUteach Program Coordinator to look at trends in enrollment from the enrollment of the first students in Fall 2015 through Fall 2017 enrollment.

Focus groups were conducted with current WVUteach students to gather qualitative data on the program. Focus groups are semi-formal conversations with a selected group of participants about a topic of particular focus where the interviewer establishes a dialogue with participants through a series of predetermined questions. Focus group methodology provides a means to explore what participants think about a topic and why they think the way they do (Liamputtong, 2011). In this program evaluation, focus groups were used to gather information about the reasons that students chose to participate in WVUteach and what factors influenced their decisions to remain in the program. In the focus group, students were asked what contributed to their decision to pursue teacher certification through WVUteach, their prior experiences with teaching, and their sense of self-efficacy in STEM teaching (see Appendix A for protocol). The students also answered questions about their career intentions upon completion of their bachelor degree program. The participants were encouraged to provide additional information they believed could provide greater insight into WVUteach. Their responses in the focus group provided a greater social context for determining strengths and areas of improvement in the recruitment and retention efforts of WVUteach.

WVUteach Master Teachers participated in interviews. Because the teachers' roles and experience with WVUteach differ greatly, speaking to them individually in interviews provided the opportunity to gather information on different aspects of the program. The Master Teachers answered questions based on feedback they received from ongoing conversations with students and questionnaires students completed for WVUteach, which were not available for review during the program evaluation. Interview questions focused on how students say they came to 
learn about WVUteach, why they enrolled in Step 1, what their reactions were to their teaching experiences, and what the students' future intentions were (see Appendix B for protocol).

\section{Procedure}

Quantitative data was obtained from the WVUteach Program Coordinator. The WVUteach Program Coordinator was directly involved in the recruitment of students into WVUteach. She also worked with students in the WVUteach Club where WVUteach students develop leadership skills and provide support for each other and for the WVUteach program. The coordinator provided an overview of the current activities used to recruit and retain students and any changes that had been made to activities since the beginning of the program in 2015 . Data collected included the number of students enrolled in all courses from the implementation of WVUteach in Fall 2015 through Fall 2017.

Internal Review Board approval was received for collection of data from WVUteach students through focus groups and WVUteach Mentor Teachers through interviews. A focus group was conducted with students who completed Step 1 and Step 2 and were enrolled in at least one course beyond Step 2. The focus group too place in a private setting to maintain confidentiality. The evaluator informed participants of the purpose of the focus groups and the manner in which data would be stored, shared, and reported. The session was recorded using audio equipment. Recordings were submitted to a company that provides transcription services. The company used 128-bit SSL encryption and the professionals who viewed the files signed a strict confidentiality agreement provided by the company. The transcripts were reviewed for accuracy, and all participants' names were removed from the transcript.

To collect additional data about students who participated in Step 1 and Step 2 and to learn more about the WVUteach program and processes, WVUteach Master Teachers were interviewed. WVUteach Master Teachers taught the Step 1 and Step 2 courses. They also participated in the recruiting events such as STEM classroom presentations and booths at events. Some Master Teachers also supervised students during their apprentice teaching and worked with students in the WVUteach Club. The Master Teachers talked with students during recruitment and in their Step 1 and Step 2 courses. Because their offices were located in the WVUteach House, they also had the opportunity to interact with other WVUteach students not currently in Step 1 or Step 2. As a result of their various contacts with students, their knowledge 
of many facets of the WVUteach program, and their interaction with the data collected from students in the program and students who leave the program, the WVUteach Master Teachers provided insights that helped address the enrollment and retention of students in WVUteach and the career intentions of students who persisted in the program.

\section{Data Analysis}

Data on enrollment from the first semester of the WVUteach program in Fall 2015 through the Fall 2017 semester were obtained from WVUteach. The data were summarized and analyzed for trends in enrollment and retention. Trends from one term to the next and overall summaries for persistence in WVUteach were calculated.

Qualitative data were collected through a focus group with WVUteach students and interviews with WVUteach Master Teachers. The data for the focus group were coded in several stages. During the first round of coding, statements referring to the major categories of enrollment, retention, and intentions were identified. The evaluator then isolated the statements for each major category and identified themes in the minor categories. For example, the minor categories in enrollment related to recruitment activities, enrollment benefits, and previous experiences. The statements were then coded using these minor categories. Another round of coding was completed to identify key words and phrases within the minor categories. These key words and phrases were collapsed into subcategories. For example, subcategories for recruitment activities included New Student Orientation, introductory STEM course presentations, advisors, and the course catalog.

Codes were developed individually for focus group data and interview data. The codes from the focus group were set aside, and the same process was used to develop codes for the Master Teachers' interview data. The codes were then combined to develop a code structure that provided a consistent set of codes for student and teacher data. In some instances, new subcategories were added. For instance, the Master Teachers mentioned several benefits to enrollment in WVUteach that fell into five subcategories: personal, social, academic, professional, and financial. In other instances, the codes were reworded and clarified to capture similarities and differences in descriptions provided by students and Master Teachers. The main differences were seen in descriptions of previous experiences. After the codes were finalized, the focus group and interview data were recoded using the codes outlined in Figure 3. During 
this final round of coding, additional notations were made to indicate whether statements were positive, negative, or neutral in the areas of recruitment activities, previous experiences, and teaching experiences in the WVUteach introductory courses.

The coding completed for enrollment, retention, and intentions was set aside, and the data were examined for statements involving students' self-efficacy in teaching. In the focus group, students were asked specific questions based on current theory to better understand their selfefficacy; however, other statements made by students during the focus group provided additional insight into their self-efficacy. Codes were predetermined based on the seven aspects of teaching self-efficacy based in theory: teacher identity, use of a variety of instructional strategies, assessment of learning, individualized instruction, classroom management, student engagement, and student motivation. These codes were applied to all relevant statements in the focus group data, not solely to students' answers to the specific self-efficacy questions. Interviews with Master Teachers were not coded for student self-efficacy.

The process of coding the focus group and interviews was completed in several stages with each stage completed on a different day. After the codes were finalized, data were coded without looking back at the previous coding results. The evaluator compared the two sets of coded data look for inconsistencies in applying codes. Time constraints did not allow for a second coder to verify the evaluators' coding.

\section{Results}

\section{Evaluation Question 1: Looking at historical data, what trends have occurred in enrollment and retention in Inquiry Approach to Teaching, Inquiry-Based Lesson Design, and further courses in WVUteach since Fall 2015?}

Historical data were examined to develop a summary of the trends that occurred in enrollment and retention in Step 1, Step 2, and further courses in WVUteach from Fall 2015 to Spring 2018. WVUteach provided WVUteach course enrollment and completion data beginning with the first class of students in Fall 2015, Table 2. In Fall 2015, 27 students enrolled in the first course, ARSC 120 Inquiry Approach to Teaching, Step 1. According to WVUteach, because Fall 2015 was the first term for WVUteach, enrollment was limited. After completing Step 1, 16 of the 27 who had enrolled in Step 1 continued on to take Step 2 in the following term. Figure 4 displays the number of students enrolled in Step 1 along with the number of students 
enrolled in Step 2 the following term. After Spring 2016, the number of students enrolled in Step 2 may have included students who waited one or two terms between the completion of Step 1 and enrollment in Step 2. Approximately, 67\% of the students who completed Step 1 in Fall 2015 enrolled in Step 2 the following semester, Enrollment in Step 2 in Fall 2016 was 82\% of the number of students completing Step 1 in the prior semester. Data were not available indicating the number of students enrolled in Step 2 in Fall 2016 who had completed Step 1 in a semester other than Spring 2016. Enrollment in Step 2 in Spring 2016 and subsequent semesters was $69 \%, 39 \%$, and $49 \%$ of the number of students completing Step 1 the prior term, Figure 5.

Trends beyond enrollment in Step 1 and Step 2 were difficult to calculate because students were permitted to enroll in Step 2 and a course beyond Step 2 concurrently. This dual enrollment explains why the number of students enrolled in Knowing and Learning (UTCH 221) in Fall 2016 was greater than the number of students who completed Step 2 prior to the Fall 2016 semester, Table 2. Examination of individual student data rather than course enrollment numbers would have provided a more accurate picture of enrollment trends

Some trends can be seen in cumulative enrollment in Step 1 and Step 2 across the first two years of the program, Figure 6. Of the 123 students who completed Step 1 in the first three semesters of the program, $73 \%$ went on to enroll in Step 2. Of the 81 students who completed Step 2 in the first two years of the program, 44\% stayed in the program for at least one more course by the end of the second year of the program. Finally, by the end of the second year of WVUteach, 23\% of the students who enrolled in Step 1 in the first three semesters had completed at least one course beyond Step 2.

\section{Evaluation Question 2: According to WVUteach students and Master Teachers, what reasons did students state for their decisions to enroll in WVUteach?}

Current WVUteach students and Master Teachers shared their insight into what influences students in their decisions to enroll in WVUteach. The students and teachers first shared their experiences with recruitment activities, what did and did not seem to work well. The results are organized by type of recruitment activity. The students and teachers then shared their thoughts on the personal, social, academic, professional, and financial benefits that attract students to enroll in WVUteach. 
The first recruitment activity was providing information for students and parents at New Student Orientation (NSO). The Master Teachers shared their observations of mixed reactions when parents and students came to the WVUteach information table. Some parents encouraged their students to give the program a try. Other parents discouraged their students from considering WVUteach, citing low pay in teaching compared to other potential STEM fields. One Master Teacher pointed out that NSO was a great opportunity to reach students while they are creating their schedules and considering their options. A focus group student recalled his memory of joining four or five other students during scheduling in the computer lab as they moved off to another section of the room to learn more about WVUteach. Another focus group student, however, felt that not enough emphasis was given to WVUteach beyond quick directions on where to learn more about the program. Based on the comments from the students and Master Teachers, NSO may have provided minimal benefits for recruitment of students.

Next, once classes began in the Fall and Spring semesters, the Master Teachers worked to reach students again. WVUteach faculty and staff reached out to instructors of introductory courses for an opportunity to talk to large groups of students during lecture classes. According to the Master Teachers, fitting all they want to share into three or four minutes was a challenge, although they believed they had refined the process. Another challenge mentioned by the teachers was selecting the best courses to target. They found that almost no students in the courses with smaller class sizes expressed interest in WVUteach in comparison to the courses with close to 200 students in a lecture hall. One teacher also explained the challenge they faced in selecting the mathematics courses to visit. He said the mathematics department provided a list of recommended courses to visit, but WVUteach thought the students were too old to target. After visiting the smaller, lower level mathematics courses with no students enrolling, the WVUteach faculty and staff determined that the larger mathematics courses, while comprised of older students, constituted a better investment of their time. The Master Teachers discussed the balance of the time they had available to reach out in lecture classes and how that impacted the introductory science and mathematics sections they chose for their presentations. One teacher did explain that the presentations were helping spread the word. The teacher mentioned that, when polled, fewer than half of the students in the presentations had heard of WVUteach at the beginning of the recruiting week, but by the end of the week, the majority of the students said they had already had a visit in one of their classrooms. One focus group student did state that 
had it not been for the lecture presentations, he would not have known that WVUteach was an option.

Another point of contact for students was advisors. Getting the word out to advisors was a struggle for WVUteach. One focus group student said that his experience was that some advisors did not know how the program worked. Another student said his first exposure to WVUteach was through his advisor, but he believed that if he had a different advisor he would not have heard about the program. Finally, the remaining student explained that he could not find information about WVUteach in the course catalog, which made it difficult for both him and his advisor to know what classes he needed to take.

The Master Teachers stated that posters and emails were some of the less than successful ways of recruiting students. One teacher pointed out that "students don't always listen really well." The teachers also mentioned that students do not read their emails or look at posters. These methods relied on student initiative.

Of all of the recruiting methods, the students and Master Teachers said that the ways of getting the word out that seem to work best were the ones that brought the message to students where they were, such as NSO, introductory STEM lecture courses, academic advising, and various college events. They mentioned that one advantage of these recruitment methods was the direct contact with students who many not pay attention otherwise. Another advantage was the opportunity for students to ask questions about WVUteach, such as what the classes are like and how their time would be spent. The key to the success of these approaches was visibility and timing in relation to when students could act on their options.

Both the students and the Master Teachers noted the need to highlight the benefits that are likely to attract students to WVUteach. They shared the personal, social, academic, and financial benefits for students. Students in the focus group shared what benefits were of most importance to them, and WVUteach Master Teachers shared the benefits of WVUteach that they shared with students.

One of the key personal benefits that all of the focus group students mentioned was options. One student majoring in chemistry questioned, "Do I really wanna spend the rest of my life staring at Erlenmeyer flasks and test tubes?" The Master Teachers explained that a teaching certification provides some reassurance that there will be other career options available at graduation or in the future. Another student stated that he wants to further his education after his 
bachelor's degree, and a teaching certification would allow him to have a career while continuing his education. One of the Master Teachers explained that teaching certification provided a sense of security and flexibility to find a job just about anywhere.

The Master Teachers shared information about the social benefits for students. One Master Teacher shared an experience of three students who were assigned to work together: a mathematics major, a forestry major, and another STEM major. The boys, who became best friends, may never have met outside of WVUteach. The Master Teachers said it was very common for students to become friends and gather socially outside of class. Another teacher mentioned WVUteach Club and the opportunity the organization provides for students to interact socially with other STEM students.

The Master teachers also explained the ways students benefit academically from participation in WVUteach. They explained how Step 1 and Step 2 one-credit courses allowed students to try teaching without making a long-term commitment. One teacher pointed out that a student could discover that he did not like teaching with no lost time during the trial period. $\mathrm{He}$ further explained that a student who discovered that he did like teaching could earn a teaching certificate within the time he already planned for a regular degree program. Another Master Teacher stressed that students did not have to decide whether they wanted to teach right away; they could earn the teaching certificate and decide later. One teacher explained added benefits that were introduced to students in WVUteach after the program was implemented. Students earned service credits from their time in the classroom and an honors credit option for Step 1 and Step 2 were added. The teacher noted that the honors option seemed to have encouraged more honors students to try out the program.

Finally, the Master Teachers frequently pointed out the professional benefits of taking even the introductory courses. They stated that even if students never plan to teach, they had the opportunities to develop presentation and public speaking skills while getting to know other people they may never have met otherwise. The Master Teachers said they explained to students how they would likely have interactions in the professional world that would require them to communicate with others, "sometimes in an educative manner." One Master Teacher pointed out the benefit of a teaching certification on a resume when applying for jobs explaining that a teaching certification would make a candidate stand out even if the job did not involve teaching. 
He went on to explain how a non-teaching job could still involve training others. The ability to teach would make the candidate, as the teacher stated, "extremely hirable."

A small added benefit mentioned by the Master Teachers was the $\$ 100$ reimbursement that students received for completing each of the introductory courses. The teachers pointed out that while the financial benefit did not appear to be a driving force in choosing to enroll in a WVUteach course, the incentive might have pushed a student to take a chance that they may not have taken otherwise. In those situations, one Master Teacher pointed out, they "simply take the class for that but then they do get hooked." Many of the benefits shared by WVUteach Master Teachers were not specifically mentioned by the focus group students as either incentives for their own enrollment or benefits that made WVUteach an attractive program.

\section{Evaluation Question 3: According to WVUteach students and Master Teachers, what interests and prior experiences contributed to students' decisions to pursue teaching certification through WVUteach?}

WVUteach students and Master Teachers were asked to share some interests and prior experiences that might have contributed to students' decisions to pursue teaching certification through WVUteach. One Master Teacher shared that some students wanted to be teachers because they had a good teacher and wanted to also make a difference while others had a bad experience and wanted to be the one to bring about change. One student said that she really wanted to be a teacher when she was little but had forgotten about it until she heard about WVUteach at freshmen orientation where she realized "I could really love that." The teachers shared that frequently students had parents or other family members who were teachers and were encouraged to become teachers, too. One Master Teacher shared that some students felt obligated to become teachers because their families expected it. He said that while this expectation was not ideal, those students did not lose anything by trying out WVUteach.

One Master Teacher shared that he believed "the vast majority of students who sign up for a STEM major and then hear about us would never have thought about going into teaching." One focus group student shared that he was always told he'd make a great engineer but learned that engineering was not as exciting as he had expected. His experiences in tutoring other students caused him to contemplate a teaching career. The teachers explained that some of the students heard about WVUteach and decided to just check it out and see if teaching was 
something they might like. Other students were not sure they wanted a career in their major and jumped at the chance to try something different. And in some cases, as one Master Teacher described, students were close to graduation and still did not know what they wanted to do in life, so they said, "I better figure this out" and gave teaching a try.

Students who never considered teaching may not have considered a teacher certification without a program that allowed them to obtain their teacher certification while completing their STEM degree. One focus group student said he would have "sucked it up" and completed his STEM degree. Another student said he would still be a STEM major. A Master Teacher believed that without a program like WVUteach, students in STEM majors would continue to focus on STEM degrees without considering a teaching certification.

\section{Evaluation Question 4: According to WVUteach students and Master Teachers, what reasons did students state for their decisions to either continue or discontinue their participation in WVUteach?}

WVUteach students and Master Teachers shared their thoughts on what kept some students in the program while other students chose to leave the program. The Master Teachers shared the patterns of students' behaviors that they observed. They explained that some students decided in Step 1 that the program was not for them. They said that other students gave one more semester a try before they decided about whether to continue. One teacher stated that once students made the decision to move past Step 1, fewer students made the decision to leave the program.

The Master Teachers shared more information about the experiences in Step 1 that might have influenced the decision to continue in the program. They explained that in Step 1, students visited an elementary classroom five times for observations and teaching. When asked about students' reactions to those experiences, one teacher believed it was split down the middle between "those who enjoy it more than they thought they would and those who enjoy it much less than they thought they would." The teachers said students frequently shared how different it was to see the classroom from the teachers' perspective as compared to their own perspectives as students. They said that many students got excited when they saw the kids really learning. One student shared with his Master Teacher his disappointment that he would have to wait until the following semester to teach again. Other students, the teachers explained, discovered how hard 
it was to teach and how difficult it was to hold students' attention. One student, as a Master Teacher recalls, came back from the teaching experience and explained that she was never having kids. However, the teachers said that it was rare that students returned from the first teaching experience hating every minute of their time in the classroom. The teachers explained that students did sometimes struggle with teaching out of their area of interest, such as a mathematics major teaching a science lesson. Sometimes students did not like working with a particular age group or they did not care for or working in a content area other than their own. One Master Teacher said he figures "if they end up liking it after that, they must really like it because you put them in like the worst scenario."

WVUteach Master Teachers shared information about support systems that were in place to encourage students who did continue in the program. WVUteach Master Teachers guided students and served as continual contacts from the first day students enrolled. When students participated in their first teaching experience, their peers and Master Teachers were available to share in their successes and their struggles. WVUteach Club was another way for students to connect with peers for receive additional support throughout their program.

The students in the focus group shared their own experiences being in the classroom and about the support they received. One student said he loved it and enjoyed everything about "the setting and environment and the idea of being a teacher". Another student said he learned that he did not want to teach elementary school after Step 1, but he loved being in the middle school during Step 2 because he was able to focus on the content more. He decided "This is something I could really enjoy doing and doing it well." Another student in the focus group said Step 1 was difficult, and he "felt like a deer in the headlights." But, his confidence improved when he taught in the middle school during Step 2. One of the students shared a final thought about starting out in the elementary school for Step 1. He said, "No matter who it is, and how confident they are in the subject matter, they're gonna know more than the third graders." All of the students mentioned the positive support that they received from all WVUteach faculty and staff as they moved through the program.

The Master Teachers shared some reasons that students had left the program after moving beyond Step 2. One teacher explained that students who would have made really great teachers decided that they just did not enjoy teaching. And, a couple of teachers recalled a couple of students who loved the little kids so much that they decided to leave WVUteach to pursue an 
elementary education degree. One of the teachers explained that some students learned the time involved to earn a teaching certification was 30 hours, not just a couple of courses, and decided not to continue in the program. For some students in more intense programs such as engineering, the students realized that they would need to stay an extra semester and chose not to pursue their teaching certification. One Master Teacher explained that some students came to the university without the mathematics skills required for their major and required additional course work that took away from their open electives. Sometimes students wanted to continue, but they either could not find the time in their schedule to add the hours, or they could not find sections that met during free time in their schedules. One Master Teacher said that students who did skip a semester tended not to come back to the program. Another teacher explained how some students made it almost to graduation and were extremely successful in WVUteach, but they participated in a summer internship in their STEM field and realized the STEM career they could have. He shared about one student who dropped out after a summer internship and said she was considering teaching in her field at the university level. She stayed involved with WVUteach Club even though she did not continue in WVUteach.

One Master Teacher said that some students came in to Step 1 with the intention to just gain some public speaking experience and then said they could see teaching as a career choice. But, he went on to say that those students did not typically enroll in Step 2. Regardless of the reason that students chose not to reenroll, one Master Teacher stressed, "it's okay not to continue because that's what the program is for." Another Master Teacher reiterated, "Teaching is not for everyone." For those students who decided that obtaining a teaching career could be an option, WVUteach provided that opportunity.

\section{Evaluation Question 5: According to WVUteach students, what was their self-efficacy in STEM teaching?}

WVUteach students who participated in the focus group were asked questions related to their self-efficacy in STEM teaching. The students shared their self-efficacy beliefs about instructional strategies, classroom management, and individualization. All of the students shared the reasons for their beliefs and what they thought would be needed to increase their selfefficacy. 
The students were first asked to describe themselves as teachers. One student shared that he still had learning and practice to do, but he felt like he was doing well. Another student was told that he had a gift for teaching, which he believed was evidenced by his enthusiasm in the classroom. He said, "the words just come out of my mouth, and it just clicks in my mind." The third student expressed a feeling of calm. He explained that he was relaxed, approachable, and "not a scary authoritative figure." None of the students specifically mentioned seeing themselves as teachers, but they all indicated that they believed that had the ability to become teachers.

When asked about their self-efficacy in using a variety of instructional strategies, the students' responses were mixed. One student believed that he was confident in his subject matter and could find different ways to teach students. He stated that he had no confidence in his ability to teach outside of his content area. One of the other students said he was not sure he was ready to try different strategies and needed more time to learn about the instructional strategies available. The remaining student was in between the other two. He said that he felt they had mostly been exposed to methods where students drive the learning, but he does not feel that is the only strategy to use. He also expressed some concern about trying to apply different strategies while trying to get teach everything that was required, stating he was not prepared to cover all of the content in the time allotted in the school calendar.

The WVUteach students in the focus group shared their beliefs about their ability to gauge students' learning. The students explained that their Step 2 course focused on evaluations, especially pre- and post-assessment. However, they agreed with each other that the Step 2 gave them limited exposure because it was only a one-credit course. The students stated that they did not feel fully prepared to determine the level of mastery and learning in their students. Two of the students attributed part of these feelings to a need to know their students, which was not possible in the short placements to that point. They said that they would feel a greater ability to gauge student learning when they had their own classrooms of students whom they worked with regularly.

The need to know the students was also a theme in the next question of self-efficacy in adjusting instruction to the proper level for individual students. One student expressed his struggle with teaching a concept one way and then trying to find another way to teach the same concept when students did not understand the content. He stressed the need for more practice in this area. Another student believed that time could be a factor in trying to adjust instruction as 
needed. The remaining student learned that adapting was not a choice, it was a necessity. He explained that a teacher must adapt to the situation and adjust the instruction or risk losing the class. All of the teachers knew what they needed to do but did not feel prepared to do it in their own classrooms.

The next area of self-efficacy in teaching was classroom management. One student said he felt very confident in his abilities to maintain an orderly classroom and address disruptive behavior. Another student stated that he learned some discipline techniques from the classroom teacher during his field placement, and he believes he can apply those same skills to his own classroom. The remaining student said he had some room to grow, but he was determined to have a "healthy amount of fear" as part of his classroom management plan.

Students were asked how they would rank their self-efficacy in keeping students on task during difficult assignments. One student expressed his strength in identifying students who were off task and pulling them back to the assignment. He did say that he would feel more confident when he was working with a classroom of his own where he would know his students and their needs. One student explained that he was not quite sure he was ready to determine what was giving students trouble so he could get them back on track. He described a teaching experience where students did not understand some terminology that he thought was common. The task became difficult, and while he did his best to explain the terms, he did say he needed more time to figure out the students' needs. In a similar comment, another student said that he believed that developing a relationship with each student would make getting the student back on track easier. But, he was not sure what he would do next if relationship was not enough.

Finally, the students were asked how well they thought they could get a student to believe they could accomplish a task. One student focused on helping girls see that they can succeed in STEM courses. He believed that girls are already outnumbered and sometimes either feel they cannot do well or prefer another subject over the STEM subjects. The remaining student was very comfortable addressing this concern. He said he would help the student work through the steps until he could say to the student, "look, you have all the tools that you needed, and you did this problem that you said you could not do." He said the key was building the student's level of confidence. The students in the focus group shared their strengths and areas in which they believe they need more practice and instruction in preparation for a career in teaching. 


\section{Evaluation Question 6: According to WVUteach students and Master Teachers, what were students' career intentions upon completion of the WVUteach program?}

One focus of the WVUteach program was to put more highly qualified STEM teachers in the classroom, particularly in West Virginia. The three focus group students were asked to share their plans after graduation. One student said he was "definitely going into the classroom." He wanted to teach in a smaller area and mentioned places in West Virginia where he might be interested in teaching; however, he suspected he may choose to live closer to his family outside of West Virginia. Another student expressed his love for the friendliness of West Virginia. He ded plan to teach, but he was not sure if it would be in West Virginia or closer to his hometown out of state. The remaining student was not sure what his future plans may be. He expressed uncertainty about a career in teaching. He said he was not sure he wanted to teach, but if he did teach, he wanted to do so in another country. While his end goal was not to be a teacher, he did want to teach at some point. He added that he had also considered continuing his education by pursuing a doctoral degree in mathematics education. He stressed that, overall, the program had changed him, and he was much happier with his degree and the choices that were available to him.

The Master Teachers shared what they had learned about the career intentions of students in WVUteach who had shared their plans. The teachers were aware that some students in WVUteach planned to teach after graduation while others wanted to teach after they tried other things such as graduate school or work in their fields. The Master Teachers reported the farther students were in their program, the more likely they were to express an intention to teach. They also noted that students who were more active and participated in WVUteach Club tended to be the students who planned to teach after graduation. The less active students shared their plans to work in industry and possibly teach when they were ready to start a family or wanted a career change.

The Master Teachers shared information about three students who were prepared to graduate in Spring 2018. They reported that all three of the students planned to teach, but they also stressed that these students were not representative of all students in WVUteach as they came into the program with a desire to teach and pursued an accelerated program. The accelerated program prepared these students to graduate ahead of their cohort. The Master Teachers were excited to share that although the graduating students were all out-of-state 
students, two of the students considered staying in West Virginia to teach. In fact, one of the students already interviewed with local schools. The teachers were told that the third graduating student was still undecided.

The focus group participants and WVUteach Master Teachers provided a thorough picture of the trends and influences on enrollment of STEM students into WVUteach, retention of students in the program, self-efficacy in STEM teaching of WVUteach students, and the intention of students to pursue a career in teaching. Their responses were used to evaluate WVUteach and allow insights into the strengths and areas of growth in WVUteach.

\section{Discussion}

\section{Enrollment}

The most important impact on enrollment was the ability to get the word out and educate students on the opportunities offered by WVUteach. The results of the input of WVUteach students and Master Teachers indicated two main areas of improvement in boosting enrollment, presentations in introductory STEM courses and overall visibility.

One main recruiting activity was presentations in introductory STEM courses. The presentations seemed to be the best way to reach larger numbers of students. The struggles with this recruitment were the inability for students to ask questions at the time they were receiving the information and difficulty for WVUteach faculty and staff to present in all of the classes. One Master Teacher pointed out that even if all STEM professors responded to the request for class time for a presentation, the Master Teachers could not get to all of the class meetings during the recruitment week. Additionally, one Master Teacher mentioned the long time between the classroom visits and enrollment for the upcoming semester. WVUteach may want to reevaluate the time frame for classroom visits and the opportunities to immediately follow up with students who show interest.

Visibility within the university was another concern mentioned by both students and Master Teachers. Students suggested that students and advisors frequently knew little about WVUteach. The classroom visits, tables at events, and presence on social media helped promote WVUteach; however, there were areas where WVUteach would have benefitted from additional visibility. One student in the focus group mentioned the lack of information in the course 
catalog. When the evaluator explored individual college information, no mention of WVUteach was easily found.

In addition to visibility among advisors and in course materials, the physical location of WVUteach presented a challenge. One Master Teacher mentioned that WVUteach House, where the introductory courses were taught, was not on the main campus, and even students who had class at the WVUteach House sometime had a difficult time finding the location. Locating WVUteach on campus or providing a satellite location, particular on the downtown campus, could boost visibility and enrollment.

WVUteach Master Teachers pointed out many benefits of enrolling in WVUteach and explained how they share those experiences with students. The feedback from the students in the focus group indicated that the benefits mentioned by the teachers were benefits that drew students to the program. Improving the recruitment through introductory stem courses and increasing visibility would allow more students to learn about the benefits that attracted current WVUteach students to the program.

\section{Retention}

Because Step 1 was designed to provide an opportunity for students to decide whether they wanted to pursue a teaching certification, lower retention in Step 2 would be expected. A greater drop in students would be expected after Step 2. Once students continue beyond Step 2, most students should be committed to completing the program. Overall, this was the trend observed in the data.

One area of concern seen in the trend of the data was in the Fall 2017 and Spring 2018 enrollment in both Step 1 and Step 2. The enrollment in Step 1 for both terms was only slightly lower, but the retention of students from Step 1 to Step 2 in both terms was considerably lower than in previous terms. Less than half of the students completing Step 1 enrolled in Step 2. Because this drop occurred in consecutive semesters, students' reasons for not reenrolling should be evaluated along with any program changes made between the 2016-2017 and 2017-2018 school years. Particularly, WVUteach may want to look at any changes in the students being recruited during this time, such as an increase in enrollment of junior and seniors, or changes in the messages being used during recruitment that may have led to an increase in students looking for short-term academic or personal benefits. 
One area in which WVUteach could address retention is in the dissemination of information to potential students. Some students come into the program expecting something different from what they encounter. For example, the Master Teachers shared that some students think they will take a couple of courses and be certified to teach. This misunderstanding may relate back to the opportunity for students to ask more questions following the presentations in the introductory STEM courses. To better understand why students leave the program and to address some of those reasons, WVUteach could survey students at the beginning, middle, and end of each STEM course to determine what conceptions they have of the program and how those conceptions change over time. The key to a healthy program is retaining the students that enroll.

\section{Students' Intentions}

One important focus of WVUteach was increasing the number of highly qualified STEM teachers in West Virginia classrooms. First, STEM students needed to be enrolled and retained. Second, STEM students who earned their teaching certification needed to choose to teach. And third, the certified teachers needed to stay in West Virginia. Once students were enrolled and persisted in the program, they needed to complete the program with their teaching certification and plans to teach. The students' self-efficacy for STEM teaching was evaluated to better understand whether students felt prepared to teach in their own STEM classroom after graduation. The students who participated in the focus group shared the areas in which they believed they were prepared to teach and the areas in which they needed more practice or instruction. Further study of WVUteach students' self-efficacy in STEM teaching at several points in their program could lead to adjustments in the curriculum to ensure the students receive the support that they believe they need.

This evaluation was not able to fully address students' intentions to teach in STEM classrooms or their intentions to remain in West Virginia because no students had yet graduated from the program. Of the three WVUteach students expected to graduate in Spring 2018, all of whom are from out of state, at least two of the students wanted to stay in West Virginia. Knowing what about their teaching experiences or experiences in West Virginia encouraged them to stay would help WVUteach plan experiences that help STEM students choose to remain in West Virginia and teach. One of the Master Teachers mentioned that there was, at the time of 
this evaluation, no job placement assistance for students graduating from WVUteach. Helping students navigate the job opportunities in West Virginia and connecting students with county school boards in recruiting events may help keep more STEM students in West Virginia.

\section{Recommendations and Other Potential Considerations for WVUteach}

The evaluation of WVUteach in the areas of enrollment, retention, and students' intentions upon graduation was a formative evaluation. The purpose of the evaluation was to examine the extent to which WVUteach was achieving its goals and determine what design or implementation needs should be addressed. A continuation of this program evaluation should be conducted to include more input from stakeholders for a more complete discovery phase. A more complete discovery phase would provide opportunities for assimilation. The WVUteach program, while utilizing the UTeach model, did have components unique to West Virginia University. The program would benefit from a full evaluation of its current processes. Change can happen when stakeholders come together and examine the current components and activities of the program and work together to find solutions for areas of potential growth.

Based on the data collected from WVUteach faculty, staff, and students, the evaluator recommends the following be considered in furthering the discovery phase and proceeding with the assimilation phase of a full program evaluation.

(1) Examine the process of recruiting students through presentations in introductory STEM courses to determine if all STEM students are receiving information and to ensure students have ample opportunity to immediately follow up with WVUteach faculty and staff.

(2) Assess the impact of the current recruitment practices in reaching STEM students at the best time of the semester and with the right access to information.

(3) Increase visibility for WVUteach in both physical location and online presence.

(4) Examine drop in enrollment and retention in Step 1 and Step 2 in Fall 2017 and Spring 2018 for any changes in recruitment or in the introductory courses.

(5) Examine potential cohort effects such as GPA and STEM majors.

(6) Explore the possibility of providing job placement assistance for students in West Virginia schools. 
WVUteach recruits students in the early stages of their STEM major through New Student Orientation, introductory STEM courses, various college events, student advising, posters, and emails. Focus group students mentioned their perceived lack of visibility of the WVUteach program. Master Teachers noticed an increase in awareness of the program as they visited introductory STEM courses. Considering both of these views, WVUteach might consider a survey of underclassmen to determine the extent to which their message is reaching students. Conducting the survey at various time points during the semester could also help determine the best timing for classroom visits and the best methods for following up with interested students.

Visibility of WVUteach both physically and online warrants additional investigation. The physical location, as mentioned by Master Teachers, may keep some students from enrolling in Step 1 and Step 2 courses. A downtown location for these courses would be closer to the Eberly College of Arts and Sciences which is housed on the downtown campus. Locating the offices on the downtown campus could potentially increase access to students who want to additional information about WVUteach. In additional to physical visibility, WVUteach does not appear in some common searches for pathways to teaching at WVU. Coordination with other current teaching programs to provide a more comprehensive list of pathways to teaching could improve WVUteach's online presence.

The introductory semesters of WVUteach include semesters of strong enrollment and retention and semesters of lesser enrollment and retention. Ongoing surveys and communications with students would be helpful in following up on program changes that might be impacting enrollment and retention. Document analysis of the recruiting material, scripts, and activities may uncover underlying changes that have resulted in changes in enrollment for specific semesters. Additional exploration of economic and policy changes in the region may also help WVUteach faculty and staff adjust their recruitment material and scripts to reflect current student needs.

In addition to examining external influences on enrollment and the internal activities of WVUteach, faculty and staff could benefit from a review of the demographics of students enrolling in WVUteach. Students may differ in GPA, choice of STEM major, semesters remaining when they enroll in the program, and other underlying factors that may influence the composition of the students in the introductory courses. Understanding these differences and how they impact enrollment and retention will provide information that can be used to refine 
enrollment practices and follow up with students as they make the decision to continue in WVUteach. While all students are encouraged to try the program in the introductory courses, the desired outcome is to recruit students who will eventually enter into a STEM teaching position in the K-12 school system.

To facility the overarching goal of increasing the number of highly qualified STEM teachers in West Virginia, WVUteach could consider job placement assistance for students would be interested in teaching in a West Virginia school. WVUteach students could participate in resume writing workshops, mock interviews, portfolio preparation assistance, and job fairs. Students could also receive assistance in identifying available positions in West Virginia that are not always posted on the state website. WVUteach might consider reaching out to county school boards with information about the WVUteach program and the benefits of hiring students who have completed WVUteach.

The recommendations for WVUteach were based on the results of this formative program evaluation. The collection of additional data and further examination of current practices would provide greater insights into the next steps for the WVUteach program. Moving into the assimilation phase of the program evaluation would involve meeting with the stakeholders to discuss the findings and determine the most appropriate changes that could be made to enhance the strength of WVUteach and improve the programs function and outcomes.

\section{Conclusion}

\section{Limitations}

The key to a constructivist evaluation was the involvement of the stake holders, and the support and involvement of the stakeholders was critical to a successful evaluation. The faculty and staff of WVUteach did not seek out this program evaluation. They volunteered their time and their resources for the purpose of this thesis. As a result, access to documents such as students' demographic information, responses to student surveys administered by WVUteach, and data comparing WVUteach to other UTeach programs was limited. The evaluator did not meet with the Master Teachers early in the planning phases of the evaluation of WVUteach. Through the interviews with the Master Teachers, the evaluator learned the importance of meeting with all stakeholders at the beginning of the evaluation to learn more about the program and its participants and to learn about additional resources that may be useful in the evaluation. 
Of all of the stakeholders, the WVUteach students involved in the program were the ones whose input was difficult to obtain. Students early in the program, who were of most interest, did not respond to requests for their input. Their voices were only heard through the Master Teachers insights about these students. The only student input gathered was from a small selfselected group of students who wanted to share their experiences with a program that they had embraced. A more complete and diverse picture of students' experiences with WVUteach would have been provided had more students participated in the focus groups.

Finally, this program evaluation was limited to the discovery phase of the constructivist evaluation. In the discovery phase only three current WVUteach students provided information. The students had all participated in course beyond Step 1 and Step 2, indicating that they already had an investment in the program. More information was needed from students in Step 1 and Step 2 and students who chose not to continue in the program. Information was gathered from Master Teachers who work primarily with students in Step 1 and Step 2, but instructors of other WVUteach courses were not interviewed. Preliminary information was gathered and recommendations were made. The next phase in a constructivist evaluation would be assimilation of the gathered information; however, that was beyond the scope of the current study.

\section{Recommendations for Future Research}

This study raised some questions that could benefit from further study. In the area of recruitment activities, what activities were generating the highest return for their output? Were these activities saturating the market of STEM students with all of the information that they need to make the best choices? WVUteach Master Teachers shared many benefits to students beyond earning a teaching certificate. Were those benefits of importance to students? Were students aware of the hidden benefits of the program? Finally, an intended outcome of WVUteach was to increase the number of highly-qualified STEM teachers in West Virginia. Considering the number of out-of-state students who enrolled in the course, a future study could examine why out-of-state students may choose to stay in West Virginia.

Another area of interest in the consideration of teachers in the STEM field is a consideration of gender proportions in WVUteach. The list of current WVUteach students provided for this evaluation indicated an approximately equal number of male and female 
students. How does this proportion compare to the proportions of male and female students in STEM majors? How does WVUteach's proportions compare to other UTeach programs? How can WVUteach address any differences? All of these possibilities for future studies would be helpful in a full evaluation of WVUteach.

\section{Conclusion}

This study provided a starting point for a full program evaluation of WVUteach. The data collected from current WVUteach students and WVUteach Master Teachers indicate areas that warrant further investigation. The results of a full program evaluation of WVUteach could be used to help new UTeach programs and programs that provide alternative paths to teacher certification with a model of practices that have been effective in the initial years of implementation of the WVUteach program. 


\section{References}

Bandura, A. (1993). Perceived self-efficacy in cognitive development and functioning. Educational Psychologist, 28(2), 117-148.

Benedum Collaboarative Professional Development Schools (2016). The WVU five-year teacher education program: Student handbook. Retrieved from https://cils.wvu.edu/5-yr-teachered

Berger, P. L., \& Luckmann, T. (1967). The social construction of reality: A treatise in the sociology of knowledge. Garden City, N.Y: Doubleday.

Crotty, M. (1998). The foundations of social research: Meaning and perspective in the research process. Thousand Oaks, CA: SAGE.

Eick, C. J. (2002). Studying career science teachers' personal histories: A methodology for understanding intrinsic reasons for career choice and retention. Research in Science Education, 32, 353-372.

Gallahan, K. E. (2016, August 19). Officials weigh in on the urgency of filling mathematics positions in schools, The Exponent Telegram. Retrieved from www.wvnews.com

Guarino, C. M., Santibanez, L., \& Daley,G. A. (2006). Teacher recruitment and retention: A review of the recent empirical literature. Review of Educational Research, 76(2), 173208. doi:10.3102/00346543076002173

Guba, E. G., \& Lincoln, Y. W. (2001). Guidelines and checklist for constructivist (a.k.a. fourth generation) evaluation. Retrieved from https://wmich.edu/sites/default/files/attachments /u350/2014/constructivisteval.pdf

Hill, J. \& Owens, C. (2015). Education and Certification Qualifications of Departmentalized Public High School-Level Teachers of Selected Subjects: Evidence From the 2011-2012 Schools and Staffing Survey (NCES 2015-814). National Center for Education Statistics, Institute of Education Sciences, U.S. Department of Education, Washington, DC.

Ingersoll, R. M. \& Perda, D. (2010). Is the supply of mathematics and science teachers sufficient? American Educational Research Journal, 47(3), 563-594. doi:10.3102/0002831210370711

Liamputtong, P. (2011). Focus group methodology: Principles and practices. Thousand Oaks, CA: SAGE. 
Luft, J. A., Wong, S. S., \& Semken, S. (2011). Rethinking recruitment: The comprehensive and strategic recruitment of secondary science teachers. Journal of Science Teacher Education, 22(5), 459-474. doi:10.1007/s10972-011-9243-2

Stufflebeam, D. (2001). Evaluation models. New Directions for Evaluation, 2001(89), 7-98. doi:10.1002/ev.3

Stajkovic, A. D., \& Luthans, F. (1998). Social cognitive theory and self-efficacy: Going beyond traditional motivational and behavioral approaches. Organizational Dynamics, 26(4), $62-$ 74.

U.S. Department of Education Office of Post-Secondary Education. (2013). Preparing and credentialing the nation's teachers: The secretary's ninth report on teacher quality. Washington, D.C.

UTeach Institute. (2017). UTeach and UTeach Expansion [PDF file]. Retrieved from https://institute.uteach.utexas.edu/sites/institute.uteach.utexas.edu/files/uteach-statsspring-2017-2017june22.pdf

Vygotsky, L. S. (1978). Mind in society: The development of higher psychological processes. Cambridge, MA: Harvard University Press.

Westerlund, J. F., Radcliffe, R. A., Smith, D. A., Lemke, M. R., \& West, S. S. (2011). Profiles of U.S. science teacher candidates: Safeguards amidst the gathering storm. International Journal of Environmental and Science Education, 6(3), 213-227. 
Table 1

Identified Topics Provided from the Research

\begin{tabular}{|c|c|c|}
\hline & $\begin{array}{l}\text { WVUteach } \\
\text { Students }\end{array}$ & $\begin{array}{c}\text { Master } \\
\text { Teachers }\end{array}$ \\
\hline \multicolumn{3}{|c|}{ Enrollment } \\
\hline \multicolumn{3}{|l|}{ Activities } \\
\hline New Student Orientation & 1 & $4 *$ \\
\hline Introductory STEM course presentations & 1 & $4 *$ \\
\hline Advisors & 2 & 1 \\
\hline Course Catalog & 1 & \\
\hline Email & & 3 \\
\hline Posters & & 1 \\
\hline Regional and WVU Events & & $2 *$ \\
\hline \multicolumn{3}{|l|}{ Benefits } \\
\hline Personal & 3 & 3 \\
\hline Social & & 2 \\
\hline Academic: Timeframe & 1 & 1 \\
\hline Low Risk & & 2 \\
\hline Honors/Service Credit & & 1 \\
\hline Professional & & 4 \\
\hline Financial & & 3 \\
\hline \multicolumn{3}{|l|}{ Previous Experiences } \\
\hline Childhood Dreams & 2 & 3 \\
\hline Teachers in Family & 2 & 2 \\
\hline Teaching/Mentoring Experiences & 2 & \\
\hline Educational Experiences & & $3 *$ \\
\hline Encouragement/Discouragement & $2 *$ & 1 \\
\hline \multicolumn{3}{|l|}{ Retention } \\
\hline Teaching Experiences & 3 & $4^{*}$ \\
\hline Supports & 3 & 2 \\
\hline \multicolumn{3}{|l|}{ Drawbacks } \\
\hline Delay in Degree Completion & & 4 \\
\hline STEM Career Focus & & 1 \\
\hline Course Scheduling & & 2 \\
\hline Teaching "not for me" & & 1 \\
\hline Program Different from Expectations & & 1 \\
\hline Elementary Education Preference & & 2 \\
\hline
\end{tabular}

\begin{tabular}{lcc}
\hline & Intentions & \\
Teaching Career in the Future & $1-$ unsure, 2 - yes & 4 \\
Staying in WV & $2-$ unsure, $1-$ no & 4 \\
Graduate School & 1 & 1 \\
Industry First & & 1 \\
\hline Note: Italicized numbers indicate participants statements were negative. All other statements were \\
positive or neutral. \\
*Some statements were positive or neutral, and some statements were negative.
\end{tabular}


Table 2

WVUteach Course Enrollment and Completion by Term

\begin{tabular}{|c|c|c|c|c|c|c|}
\hline \multirow[b]{2}{*}{ Course } & \multicolumn{2}{|c|}{$2015-2016$} & \multicolumn{2}{|c|}{ 2016-2017 } & \multicolumn{2}{|c|}{ 2017-2018 } \\
\hline & Fall & Spring & Fall & Spring & Fall & Spring $^{\mathrm{a}}$ \\
\hline ARSC 120: Step 1 & $27(24)$ & $46(40)$ & $65(59)$ & $54(51)$ & $42(37)$ & 53 \\
\hline ARSC 220: Step 2 & & $16(14)$ & $33(31)$ & $41(36)$ & $20(19)$ & 18 \\
\hline UTCH 221 & & & $18(14)$ & & $18(18)$ & \\
\hline UTCH 222 & & & & $11(11)$ & & 18 \\
\hline MATH 318 & & & & & $13(12)$ & \\
\hline UTCH 420 & & & & & $4(4)$ & \\
\hline UTCH 430 & & & & & & 3 \\
\hline MATH 376 & & & & & $6(5)$ & \\
\hline BIO/CHEM/PHYS 376 & & & & $4(4)$ & & 15 \\
\hline $\begin{array}{l}\text { Total course } \\
\text { enrollment }\end{array}$ & 27 & 62 & 116 & 110 & 103 & 107 \\
\hline $\begin{array}{l}\text { Total course } \\
\text { completion }\end{array}$ & 24 & 54 & 104 & 102 & 95 & \\
\hline
\end{tabular}

Note: Completion data appears in parentheses.

${ }^{a}$ Completion data was not available at the time of analysis. 


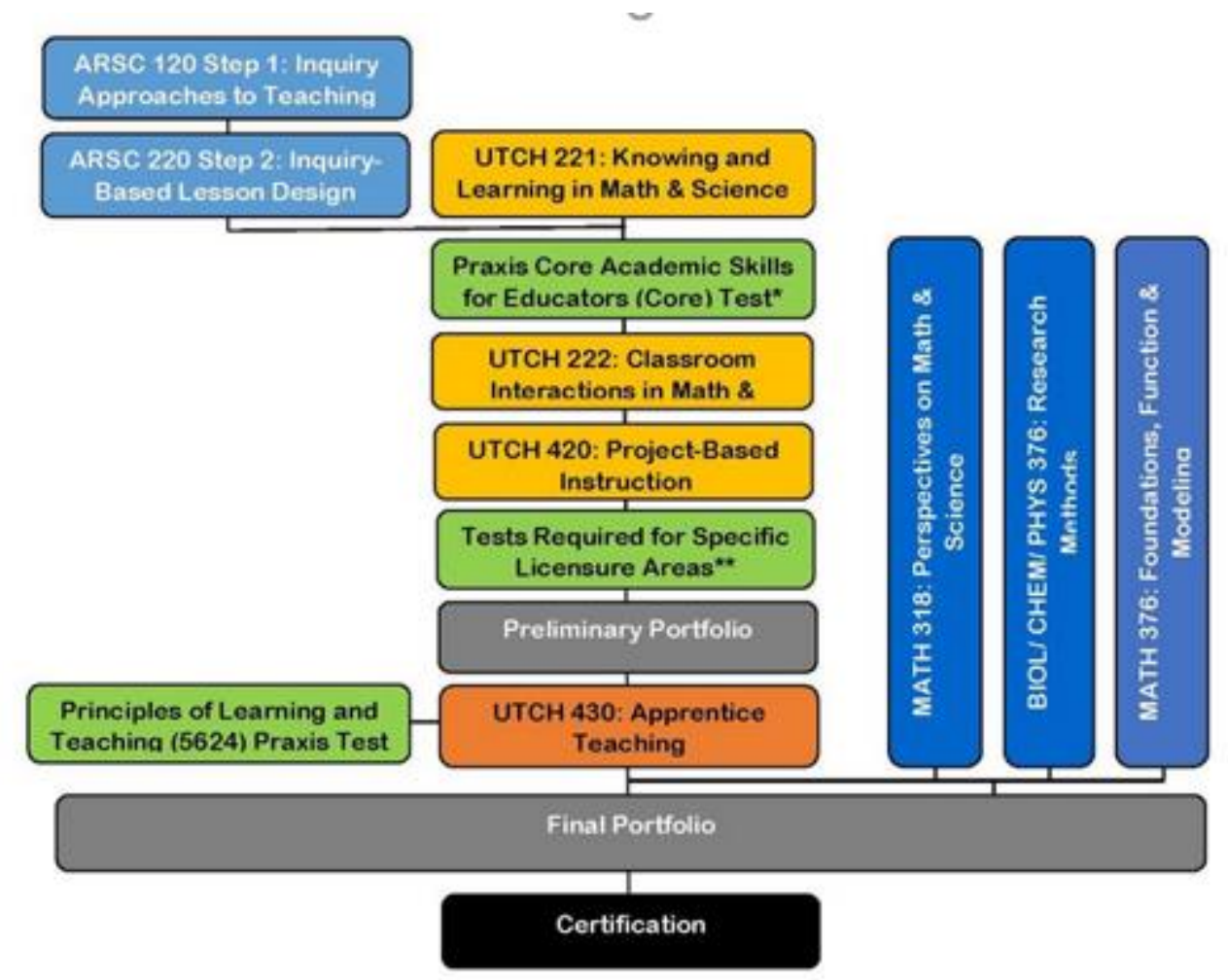

Figure 1. WVUteach Course Sequence. This figure shows the course sequence for students in WVUteach. 


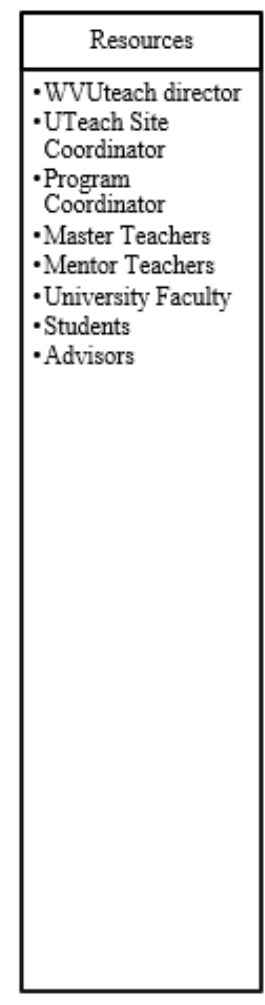

\begin{tabular}{|l|}
\hline \multicolumn{1}{|c|}{ Components } \\
\hline -Recruitment \\
-Coursework \\
- Support \\
\\
\end{tabular}
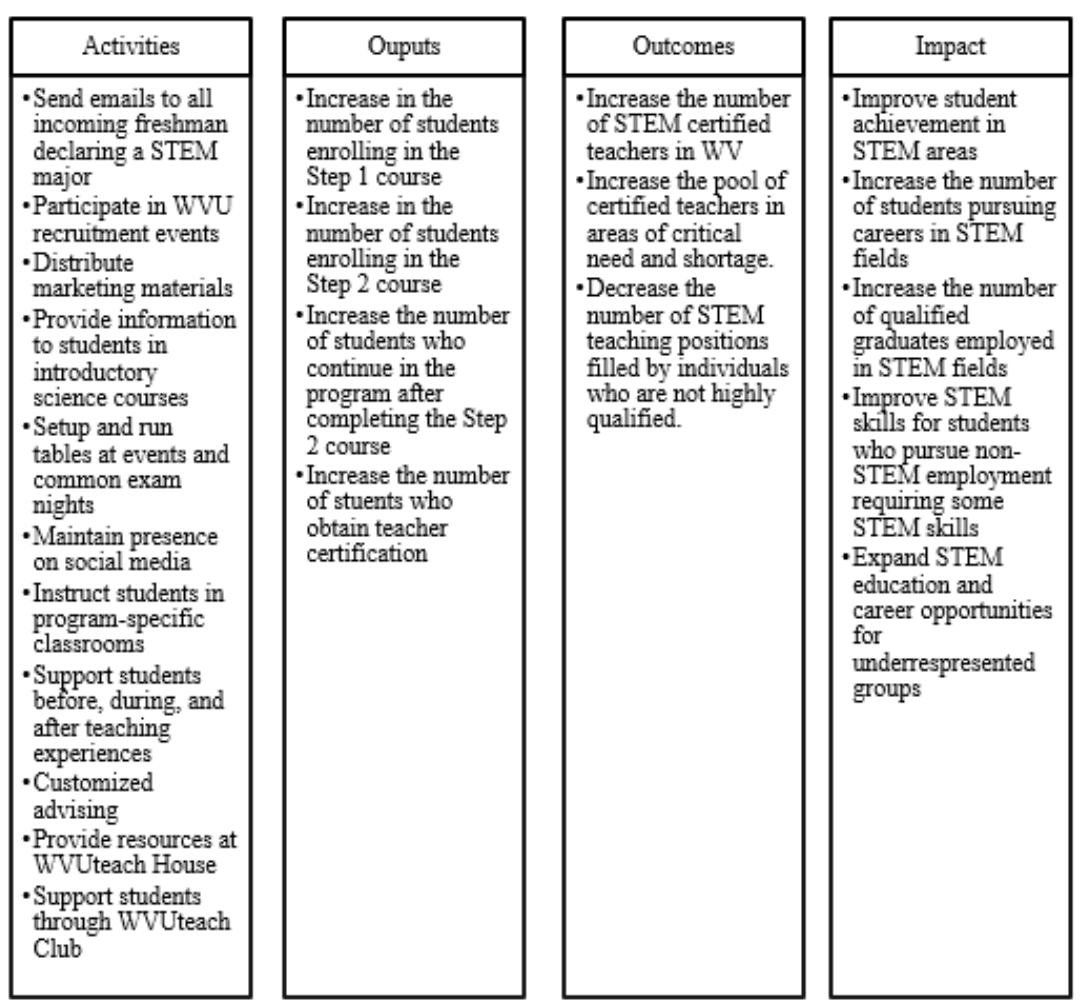

Figure 2. WVUteach Logic Model. This figure shows the logic model upon which this evaluation was designed. 


\begin{tabular}{|c|c|c|c|}
\hline Major Categories & Minor Categories & & Subcategories \\
\hline \multirow{21}{*}{ Enrollment } & \multirow{9}{*}{ Activities } & \multicolumn{2}{|c|}{ New Student Orientation } \\
\hline & & \multicolumn{2}{|c|}{ Introductory STEM Presentations } \\
\hline & & \multicolumn{2}{|c|}{ Advisors } \\
\hline & & \multicolumn{2}{|c|}{ Course Catalog } \\
\hline & & \multicolumn{2}{|c|}{ Friend } \\
\hline & & \multicolumn{2}{|l|}{ Email } \\
\hline & & \multicolumn{2}{|l|}{ Posters } \\
\hline & & \multicolumn{2}{|c|}{ Regional events } \\
\hline & & \multicolumn{2}{|l|}{ WVU events } \\
\hline & \multirow{7}{*}{ Benefits } & \multicolumn{2}{|l|}{ Personal } \\
\hline & & \multicolumn{2}{|l|}{ Social } \\
\hline & & \multirow{3}{*}{ Academic } & Timeframe \\
\hline & & & Low risk \\
\hline & & & Honors/Service \\
\hline & & \multicolumn{2}{|l|}{ Professional } \\
\hline & & \multicolumn{2}{|l|}{ Financial } \\
\hline & \multirow{5}{*}{ Previous Experiences } & \multicolumn{2}{|c|}{ Childhood dreams } \\
\hline & & \multicolumn{2}{|c|}{ Teachers in family } \\
\hline & & \multicolumn{2}{|c|}{ Teaching/Mentoring Experience } \\
\hline & & \multicolumn{2}{|c|}{ Educational experiences } \\
\hline & & \multicolumn{2}{|c|}{ Encouragement } \\
\hline \multirow{11}{*}{ Retention } & \multirow{3}{*}{ Teach Experiences } & Step 1 & \\
\hline & & Step 2 & \\
\hline & & General & \\
\hline & & Time & \\
\hline & & STEM caree & \\
\hline & & Scheduling & \\
\hline & Roodblocks & Location & \\
\hline & Kоаadiocks & Don't like tes & hing \\
\hline & & Not what the & thought \\
\hline & & Transportatic & to placements \\
\hline & & Elementary & lucation \\
\hline & & WV & \\
\hline Intentions & reaching & Out of State & \\
\hline mtentions & & Grad School & Grad School \\
\hline & Uther & Industry & Industry \\
\hline & Teacher Identity & & \\
\hline & Variety of Instruction & Strategies & \\
\hline & Assessment of Learni & & \\
\hline Self-Efficacy & Individualized Instruc & & \\
\hline & Classroom Manageme & & \\
\hline & Student Engagement & & \\
\hline & Student Motivation & & \\
\hline Miscellaneous & (Key phrases indicate & or common to & ics: questions, demographics, etc.) \\
\hline
\end{tabular}

Figure 3. Codes for Focus Group and Interviews. 


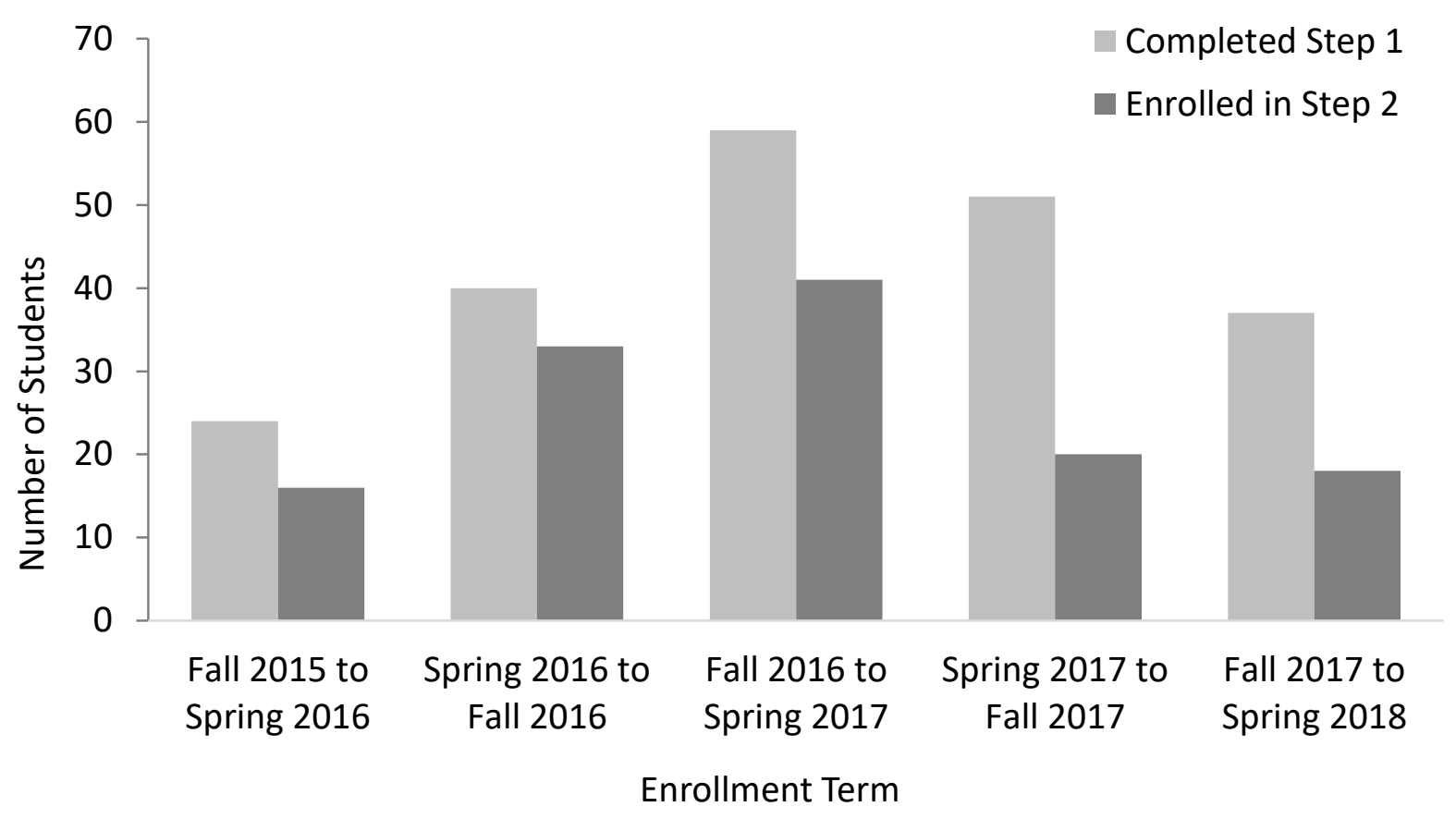

Figure 4. Number of Students Enrolled in WVUteach Introductory Courses. This figure shows the number of students enrolled in Step 1 for a term and Step 2 for the following term. Students enrolling in Step 2 in a term other than the term immediately following Step 1 are not distinguished in this figure. 


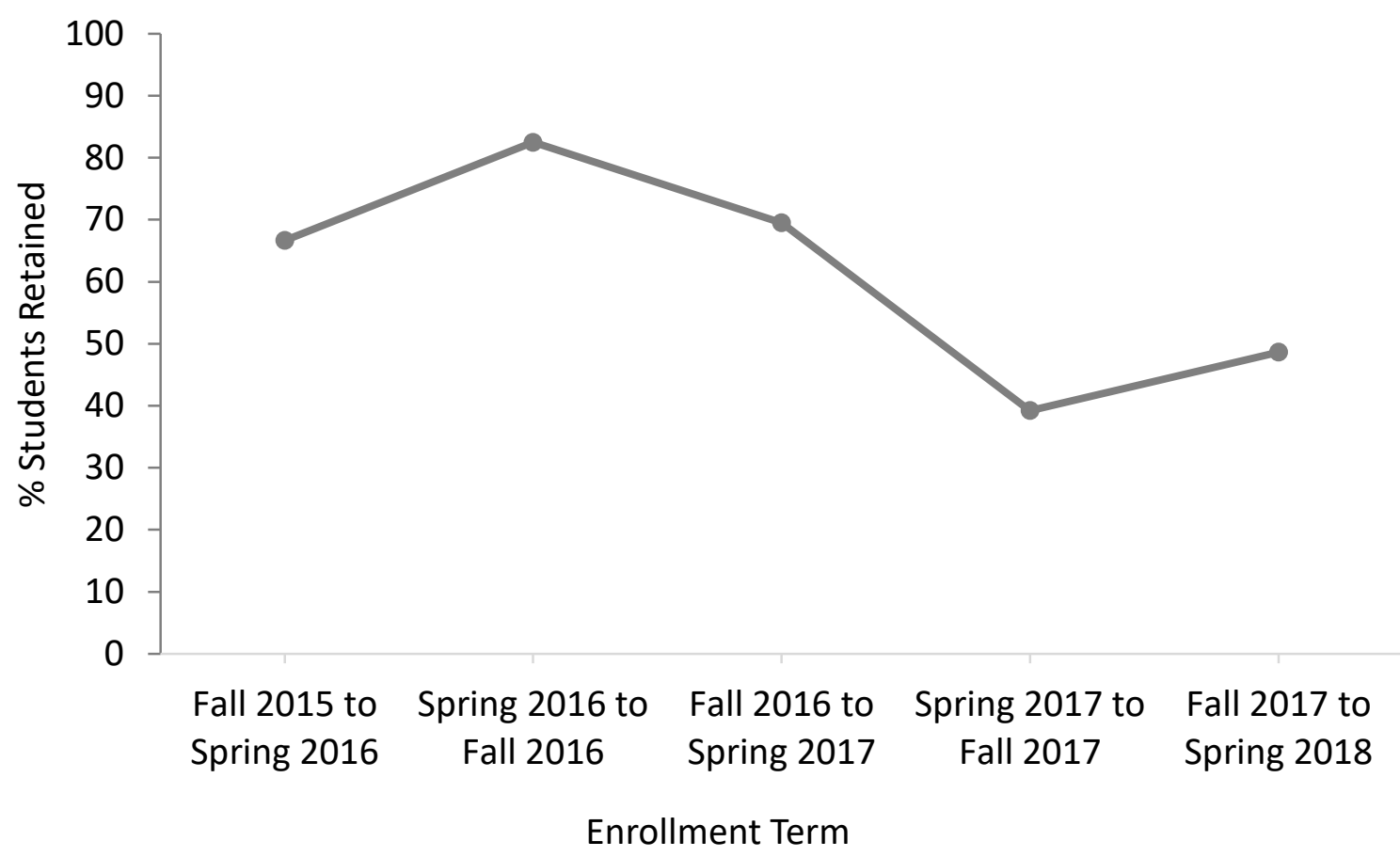

Figure 5. Percentage of Students Retained from Step 1 to Step 2. This figure shows the percentage of students enrolled in Step 1 who continue to Step 2 for the following term. Students enrolling in Step 2 in a term other than the term immediately following Step 1 are not distinguished in this figure. 


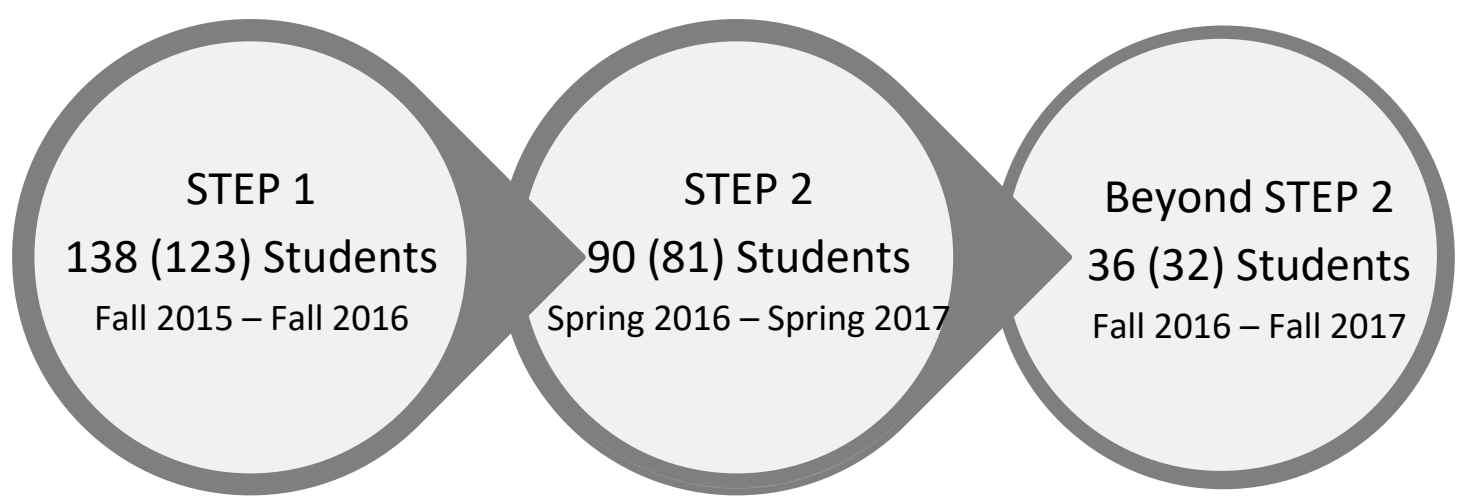

Figure 6. Persistence in WVUteach through the First Two Years. This figure shows the total number of students enrolled in each course at the beginning of the semester for the first three semesters that each course was offered. The number in parentheses reflects the total number of students who remained in the course for the full semester. This figure does not include students who may have taken a course in one term and waited one or two terms before taking the next course in the sequence. 


\section{Appendix A: Focus Group Questions}

Research Question 2: What components of WVUteach contribute to students' decisions to pursue teaching certification through WVUteach?

- How did you first hear about WVUteach?

- What interested you in WVUteach?

- What are the top 3 benefits of WVUteach that attracted you to the program?

- What do you enjoy most about WVUteach?

- What changes would you make to the WVUteach program (recruiting and/or ongoing practices)?

Research Question 3: What interests and prior experiences contribute to students' decisions to pursue teaching certification?

- Had you considered obtaining a teaching certification prior to hearing about WVUteach?

○ If yes,

- What led to your thoughts of obtaining a teacher certification?

- Who/what do you consider to be your greatest influences in your decision to obtain your teaching certification?

- If WVUteach was not offered, would you have pursued another avenue to obtain a teaching certification such as an undergraduate teaching degree or a graduate teaching degree after obtaining your STEM undergraduate degree?

- Have you had teaching experiences prior to your teaching in Step 1?

$\circ$ Describe the setting and what you were teaching.

- Did those experiences play a part in your decision to pursue a teaching certification?

- What sources of support have you received in your decision to pursue your teaching certification?

Research Question 4: What are WVUteach students' sense of efficacy in STEM teaching?

- Describe your first teaching experience with WVUteach.

○ Was your first teaching experience what you thought it would be?

- How was it the same or different?

- How many times have you taught since enrolling in WVUteach?

- How has your teaching changed through those experiences?

- How have you changed personally through those experiences? 
- Describe how you see yourself as a teacher.

- I am going to ask some questions about your potential role as a teacher. I am interested in your feedback on any questions about which you have an opinion.

○ To what extent can you

- Use a variety of instructional strategies to teach STEM content?

- Gauge students' understanding of concepts you teach?

- How much can you do to

- Adjust your instruction to the proper level for individual students?

- Provide appropriate challenges to very capable students?

- How much can you do to

- To get students to follow classroom rules?

- To control disruptive behavior in your classroom?

- How well can you

- Establish rules and routines to keep activities running smoothly in your classroom?

- Keep a few students from ruining a lesson?

○ How much can you do to

- To keep students on task on difficult assignments?

- Motivate students who show low interest in schoolwork?

- To get students to believe they can do well in school work?

Research Question 5: What are students' career intentions upon completion of the WVUteach program?

- Do you plan on continuing with WVUteach to obtain your teaching certification?

- What are your career goals?

○ Do you plan to teach after graduation?

- If yes, do you want to teach in elementary, secondary, or postsecondary?

- What courses would you like to teach?

- Where would you like to teach, in WV or another state?

- If no, would you consider substitute teaching?

- Have your career goals changed as a result of WVUteach? 


\section{Appendix B: WVUteach Master Teacher Interview Questions}

Introductory

- What is your involvement with WVUteach?

- What do you enjoy most about WVUteach?

I am interested in learning about the feedback you receive from students directly and indirectly about how they came to learn about WVUteach, why they took Step 1 and/or Step 2 courses, and what they planned to do after completing Step 1 or Step 2.

Research Question 2: What components of WVUteach contribute to students' decisions to pursue teaching certification through WVUteach?

- What do students say prompted them to enroll in Step 1 and/or Step 2?

- Do they ever mention any particular benefits of WVUteach that attracted them to the program?

- What do you think has been the most effective way to recruit students to WVUteach?

- What do you think has been the least effective way to recruit students to WVUteach?

- What types of questions do students ask you about WVUteach?

Research Question 4: What are WVUteach students' sense of efficacy in STEM teaching?

- How do students typically react to their first and subsequent teaching experiences?

- Were the experiences what they expected?

- What reasons do students give for continuing on in WVUteach?

- What reasons (expressed or otherwise observed) do students give for not continuing?

Research Question 5: What are students' career intentions upon completion of the WVUteach program?

- What do most of the students express as their career goal?

- Do they plan to teach in a k-12 setting?

- Have you encountered students who had never considered teaching before hearing about WVUteach?

- If WVUteach was not an option, do you think some of the students you have worked with would pursue certification through another avenue?

- $\quad$ Would you recommend WVUteach to a student who does not want to teach in a K-12 setting? 